\title{
Computational Assessment of Different Structural Models for Claudin-5 Complexes in Blood-Brain-Barrier Tight-Junctions
}

\author{
Alessandro Berselli ${ }^{\# 1,2}$, Giulio Alberini ${ }^{\# 1,3}$, Fabio Benfenati ${ }^{* 1,3}$ Luca Maragliano $^{* 1,4}$ \\ ${ }^{1}$ Center for Synaptic Neuroscience and Technology (NSYN@UniGe), Istituto Italiano di Tecnologia, Largo \\ Rosanna Benzi, 10, 16132 Genova, Italy \\ ${ }^{2}$ Department of Experimental Medicine, Università degli Studi di Genova, Viale Benedetto XV, 3, 16132 \\ Genova, Italy \\ ${ }^{3}$ IRCCS Ospedale Policlinico San Martino, Largo Rosanna Benzi, 10, 16132 Genova, Italy \\ ${ }^{4}$ Department of Life and Environmental Sciences, Polytechnic University of Marche, Via Brecce Bianche, \\ 60131, Ancona, Italy
}

*Corresponders email: fabio.benfenati@iit.it, luca.maragliano@iit.it

\begin{abstract}
The blood-brain barrier (BBB) strictly regulates the exchange of ions and molecules between the blood and the central nervous system. The tight junctions (TJs) are multimeric structures that control the transport through the paracellular spaces between adjacent brain endothelial cells of the BBB. Claudin- 5 (Cldn5) proteins are essential for the TJ formation. They assemble into multi-protein complexes via cisinteractions within the same cell membrane, and trans-interactions across two contiguous cells. Despite the barrier function of Cldn5 proteins and their role as targets of brain drug delivery strategies, the molecular details of their assembly within TJs are still unclear. Two different structural models have been recently introduced, in which Cldn5 dimers belonging to opposite cells join together to generate paracellular pores. However, a comparison of these models in terms of ionic transport features is still lacking. In this work, we used extended molecular dynamics simulations and free energy calculations to assess the two Cldn5 pore models and investigate the thermodynamic properties of water and physiological ions permeation through them. Despite different FE profiles, both structures present single or multiple FE barriers to ionic permeation, while being permissive to water flux. These results reveal that both models are compatible with the physiological role of Cldn5 TJ strands. By identifying the protein-protein surface at the core of TJ Cldn5 assemblies, our computational investigation provides a basis for the rational design of synthetic peptides and other molecules capable of opening paracellular pores in the BBB.
\end{abstract}

KEYWORDS: Tight junctions, Claudin-5, Blood-brain barrier, Biological pore models, Molecular dynamics, Free energy calculations.

List of Abbreviations

- BBB: Blood-brain barrier

- CLDN: Claudin

- TM:Trans-membrane

- ECL: Extracellular loop

- FE: Free energy

- MD: Molecular dynamics

- RMSD: Root-mean square deviation

- US: Umbrella sampling

- WHAM: Weighted histogram analysis method 
bioRxiv preprint doi: https://doi.org/10.1101/2022.03.03.482846; this version posted March 4, 2022. The copyright holder for this preprint (which was not certified by peer review) is the author/funder. All rights reserved. No reuse allowed without permission.

\section{INTRODUCTION}

Biological barriers are structures made of layers of tightly bound endothelial/epithelial cells that preserve the characteristics of the body compartments they separate and regulate the exchanges between them. Multimeric protein complexes named Tight junctions (TJs) ${ }^{1-6}$ hold adjacent cells together by forming strands that are visible in freeze-fracture electron microscopy (EM) images and seal the paracellular space between cells ${ }^{7-9}$.

Claudins (Cldns) are the major components of the TJ strands ${ }^{7,10,11}$. The Cldn family is composed of 27 tissuespecific homologs with a structure comprising a transmembrane four-helix bundle (TM1-4) embedded in the membrane bilayer (the TM domain). TM helices are joined by two extracellular loops spanning the paracellular space (ECL1-2) and by an intracellular loop in the cytoplasmic region, where the N/C termini are also found ${ }^{12,13}$. Cldns are known to assemble into TJs via intermolecular cis-interactions between individual protomers lining on the same cell membrane and trans-interactions between proteins contributed by adjacent cells ${ }^{14}$. TJ strands regulate the paracellular flux of ions and molecules across the various barriers via highly selective, tissue-specific mechanisms $s^{15,16}$.

The Cldn subtype 5 (Cldn5) is the most abundant TJ protein in the endothelial cells of blood-brain barrier (BBB), the highly selective interface that preserves the chemical homeostasis of the central nervous system (CNS). In particular, Cldn5 strands are responsible for the very limited BBB paracellular permeability that prevents the uncontrolled permeation of ions and small molecules ${ }^{17-20}$.

The relevant physiological function of Cldn5 proteins makes them a novel and promising target for strategies developed to deliver drugs directly to the brain ${ }^{21-25}$. However, structure-based approaches are still hampered by a lack of knowledge on the precise assembly of Cldn 5 protomers in the BBB TJs ${ }^{17}$. Only recently ${ }^{25}$, based on prior results on other $\mathrm{Cldns}^{26-28}$, two structural models of Cldn 5 complexes were introduced, both of which display a pore cavity and were so referred to as Pore I and II.

The Pore I structure derives from the model originally introduced by Suzuki et al. in Ref. 29 for the homologous Cldn subtype 15 (Cldn15, PDB ID: 4P79) ${ }^{30}$, the first member of the family to be crystallized. According to this template, cis-interactions are formed by the ECL1 domains of two neighboring protomers in the same membrane (also named face-to-face interaction ${ }^{7}$ ), with opposing $\beta$-strands arranged in an antiparallel fashion to generate an extended $\beta$-sheet across the two molecules, defining a hydrophilic surface. Moreover, two opposing dimers from adjacent cells create a tetrameric arrangement sustained by trans-interactions between the ECLs of the protomers, resulting in a $\beta$-barrel super-secondary structure in the paracellular space that encompasses a pore cavity. After the publication of the Cldn15-based model, this has been refined and validated in several studies using structural modeling and Molecular Dynamics (MD) simulations $^{31-38}$, also for other Cldns. In particular, in Ref. 37, the authors investigated the mechanism of ion permeation through the Cldn5 Pore I by calculating the free energy (FE, or potential of mean force, PMF) profiles for various ionic species. Results pointed to the lack of both cation and anion permeation, thus demonstrating that the Pore I conformation properly reproduces the function of barrier to ionic fluxes exerted by BBB TJs ${ }^{39}$.

On the other hand, the Pore II was also introduced by the same group ${ }^{34,35,40}$, based on previously modeled $\mathrm{Cldn} 5$ dimers $^{34}$. Although the structure still comprises again two facing Cldn dimers, the cis-arrangement between two protomers in the membrane of the same cell is characterized by a distinct pattern of interactions involving the TM2 and TM3 helices (also named back-to-back interaction ${ }^{7}$ ). More specifically, the authors identified a leucine zipper motif defined by the residues Leu83, Leu90, Leu124 and Leu131 of the two Cldn 5 subunits, supported by the aromatic interactions between the opposing pairs of Trp138 and Phe127 residues. The presence of this dimerization interface is consistent with the experimental results illustrated in Ref. 28. Then, similarly to the Pore I configuration ${ }^{13,40}$, the Pore II architecture is obtained by joining a couple of these dimers via trans-interactions, although it lacks the cavity-enveloping supersecondary structure distinctive of Pore I. The MD simulations illustrated in Ref. 40 demonstrate that the Cldn5 Pore II is impermeable to small molecules such as $\alpha$-D glucose but permissive to water.

However, at variance with Pore I, the Pore II model is still limitedly investigated ${ }^{34,35,40-42}$, and further studies are required to chart its structural and functional hallmarks. In particular, a detailed investigation of its ionic permeability has not been performed yet, thus hampering a thorough comparison with Pore I.

The aim of this work is to investigate the two different pore models and to assess their reliability as possible representatives of Cldn 5 complexes in the TJs of the BBB. After building the two tetrameric configurations 
bioRxiv preprint doi: https://doi.org/10.1101/2022.03.03.482846; this version posted March 4, 2022. The copyright holder for this preprint (which was not certified by peer review) is the author/funder. All rights reserved. No reuse allowed without permission.

using Cldn5 protomers modeled from the homologous $\mathrm{Cldn} 15^{30}$, we used all-atom MD simulations to refine their structures in solvated, double-membrane environments and to compute the dimensional FE profiles for the permeation of water and ions through both pores. Results show that the Pore I arrangement is structurally more stable, while both are water-permeable and present FE barriers of different heights to the passage of ions, consistently with the known role of Cldn5 in increasing the transendothelial electrical resistance and reducing the ionic paracellular permeability of the $\mathrm{BBB}^{20}$. In both conformations, the $\mathrm{FE}$ critical points correlate with the positions of pore-lining charged residues: barriers for cations are localized in proximity of the Lys65 sidechains, while those for $\mathrm{Cl}^{-}$are in correspondence of Glu146 and Asp149. The profiles for the same ions are, however, quite different in the two structures, due to distinct arrangements of the residues along the pores. Moreover, the hydration pattern of permeating ions along the pore axis shows a partial depletion of the coordinating water molecules in correspondence with the narrow regions of the pores ${ }^{33,43}$.

Our findings provide a systematic description of the two Cldn 5 tetrameric pore configurations in terms of their structural and permeation properties, indicating that they are both possible Cldn 5 assemblies in the TJs of the brain endothelium.

\section{RESULTS AND DISCUSSION.}

The tetrameric structures of Pore I and Pore II are shown in Figures 1-3, which report the arrangements of Cldn5 protomers in dimers (Figure 1), the quaternary structure of the two pores (Figure 2), and the relevant amino acids within their cavities (Figure 3), respectively.

A

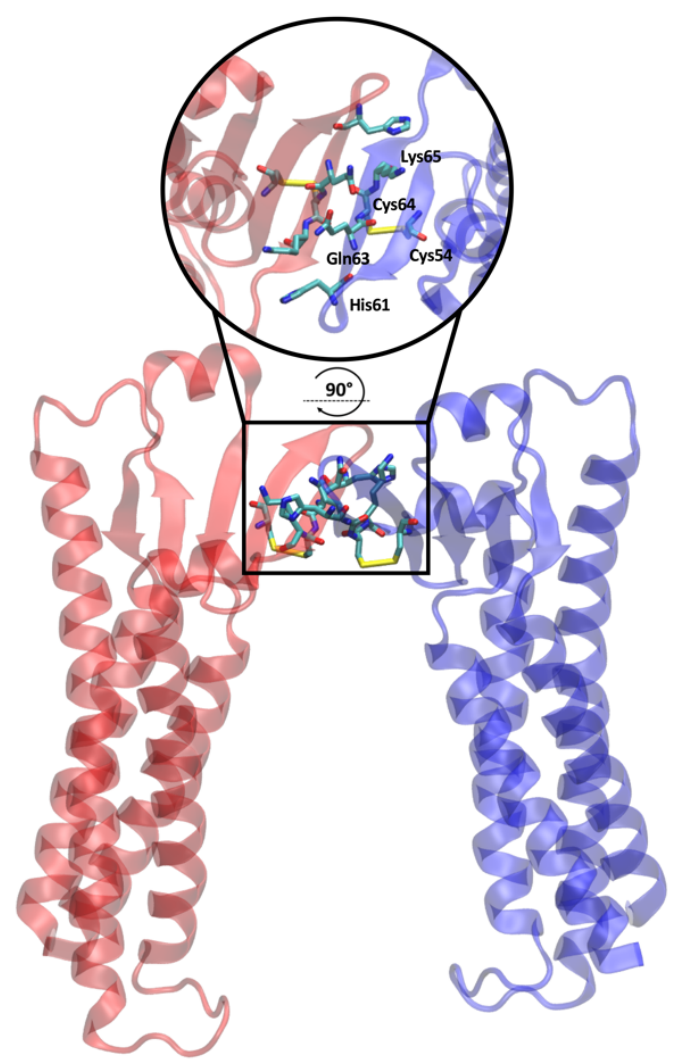

B

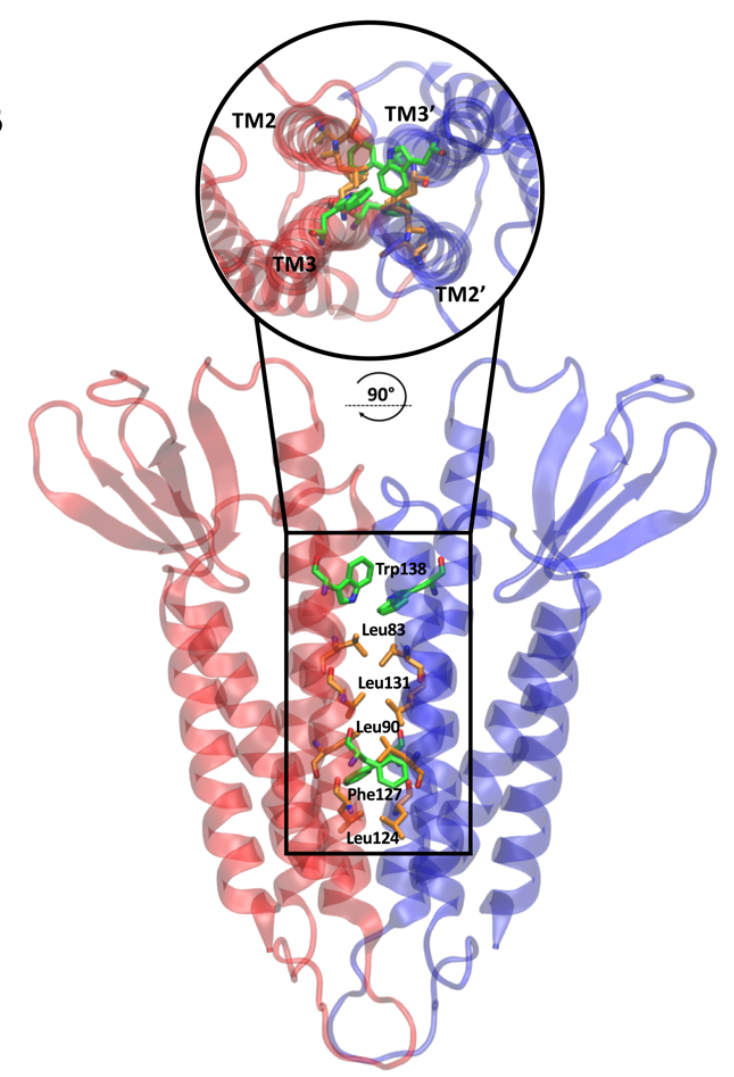

Figure 1. Structural representations of the two equilibrated dimeric structures which prelude to Pore I (A) and Pore II (B). The dimer in panel $A$ is characterized by a face-to-face interaction between the ECL1 domains of two opposite Cldn 5 protomers. The dimer in panel $B$ is formed by a back-to-back interaction and stabilized by a leucine zipper pairs in the TM2-TM3 helices of the single Cldn 5 protomers.

To construct the Pore I system, two distinct models were set-up and simulated for $1 \mu \mathrm{s}$ each. Both configurations showed a remarkable structural stability of the paracellular domains, evaluated by root-mean square deviation (RMSD) of the ECLs and cross-distances between facing, pore-lining residues. We then selected the model to be used as Pore I system based on pore size and the preservation of a hydrogen bond 
bioRxiv preprint doi: https://doi.org/10.1101/2022.03.03.482846; this version posted March 4 , 2022. The copyright holder for this preprint (which was not certified by peer review) is the author/funder. All rights reserved. No reuse allowed without permission.

involving the highly conserved Lys157 that was described as structurally relevant in Refs. 7,12. Details of the modeling steps and MD simulations set-up are provided in the Methods section, while the analysis of the simulations and the assessment of the best Pore I model are reported in the Supplementary Information file.

A

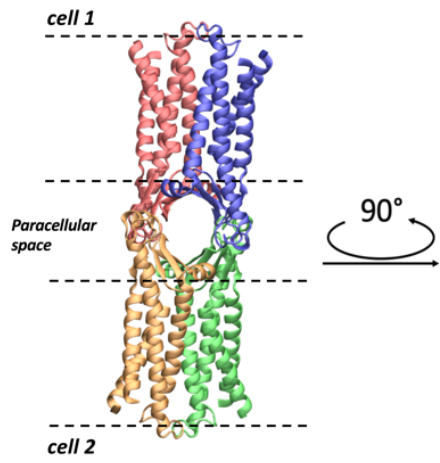

C

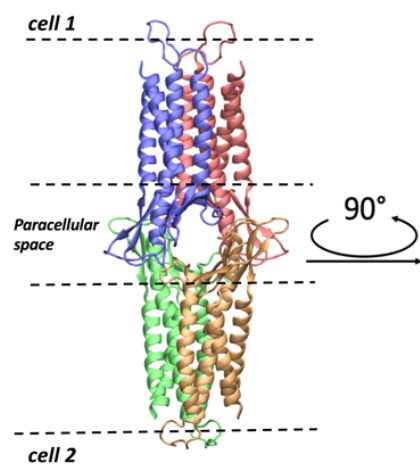

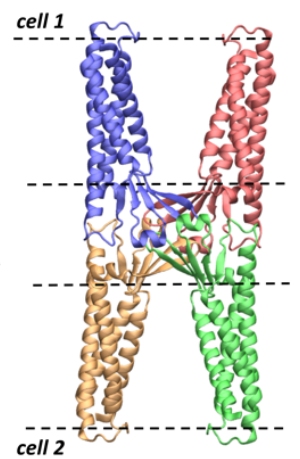

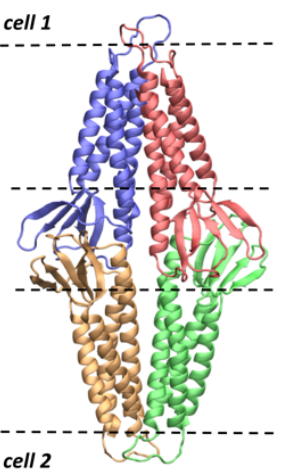

B
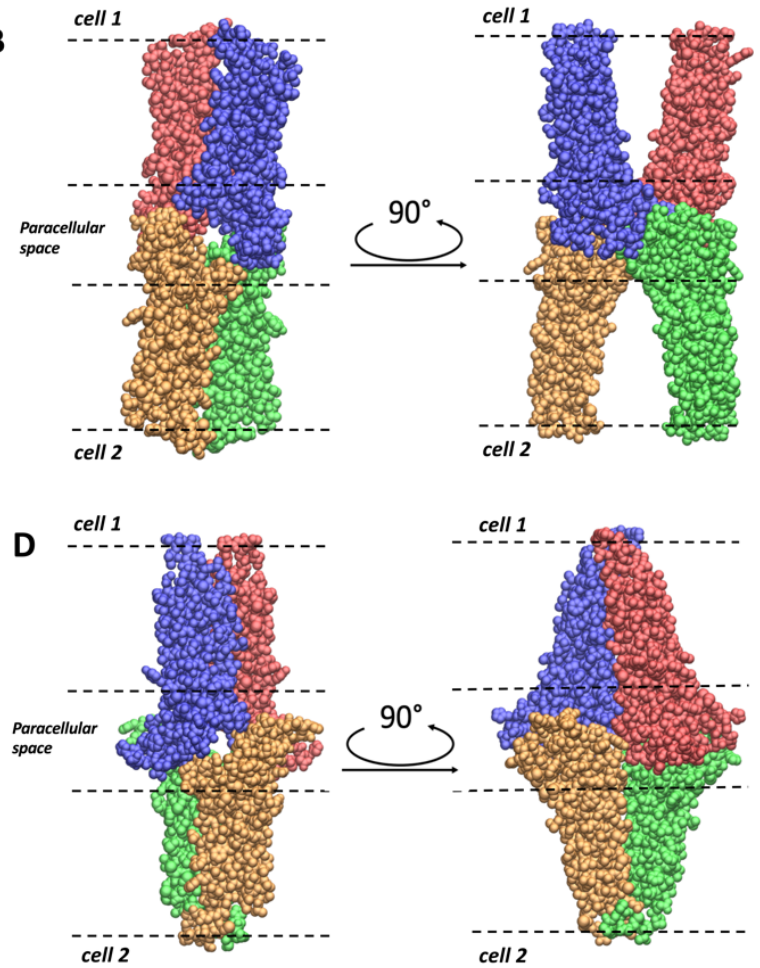

Figure 2. Structural representation of the two equilibrated single-pore models, top and side views. Pore configurations are shown in ribbon cartoon style $(A, C)$ and Van Der Waals sphere style $(B, D)$ for Pore I $(A, B)$ and Pore II $(C, D)$ models, respectively.

FE Calculations. Experimental evidence confirms that Cldn5-based TJs form an efficient barrier to the permeation of small molecules and physiological ions $s^{3,6,39,44-47}$. Here, we used the Umbrella Sampling (US) method ${ }^{104}$ to perform $\mathrm{FE}$ calculations for a single water molecule or single $\mathrm{Na}^{+}, \mathrm{K}^{+}, \mathrm{Cl}^{-}, \mathrm{Ca}^{2+}, \mathrm{Mg}^{2+}$ ions permeating across the pore cavity of Pore I and Pore II structures.
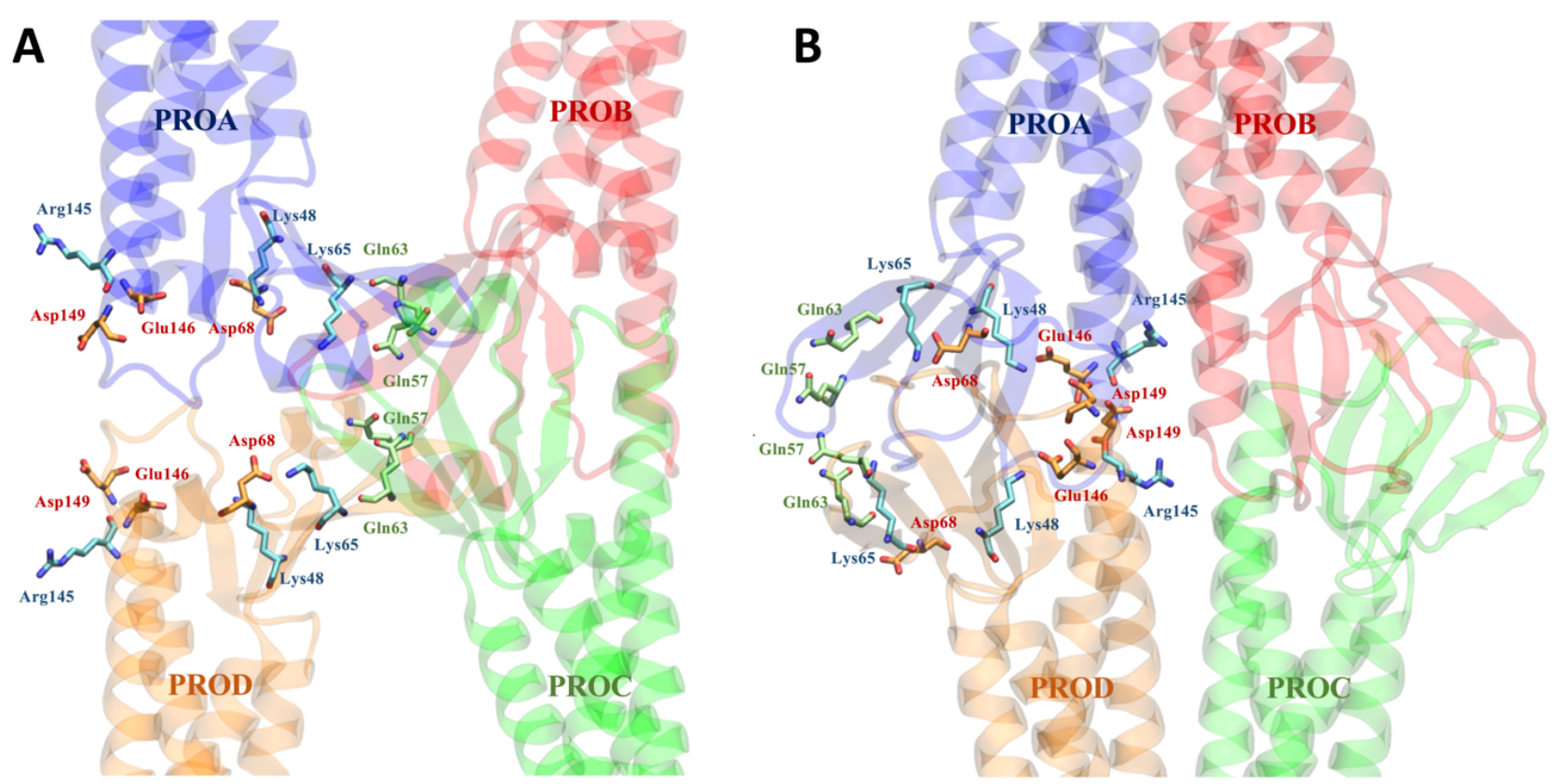

Figure 3. Locations of selected residues along Pore I (A) and Pore II (B) models. 
bioRxiv preprint doi: https://doi.org/10.1101/2022.03.03.482846; this version posted March 4, 2022. The copyright holder for this preprint (which was not certified by peer review) is the author/funder. All rights reserved. No reuse allowed without permission.

In all the US simulations, we used the projection of the position of the tagged ion (or water molecule) on the pore axis as collective variable (CV). The FE profiles obtained for the two pore models are reported in Figure 4 and Figure 5, respectively. The errors associated with these calculations were estimated via bootstrapping ${ }^{48}$.

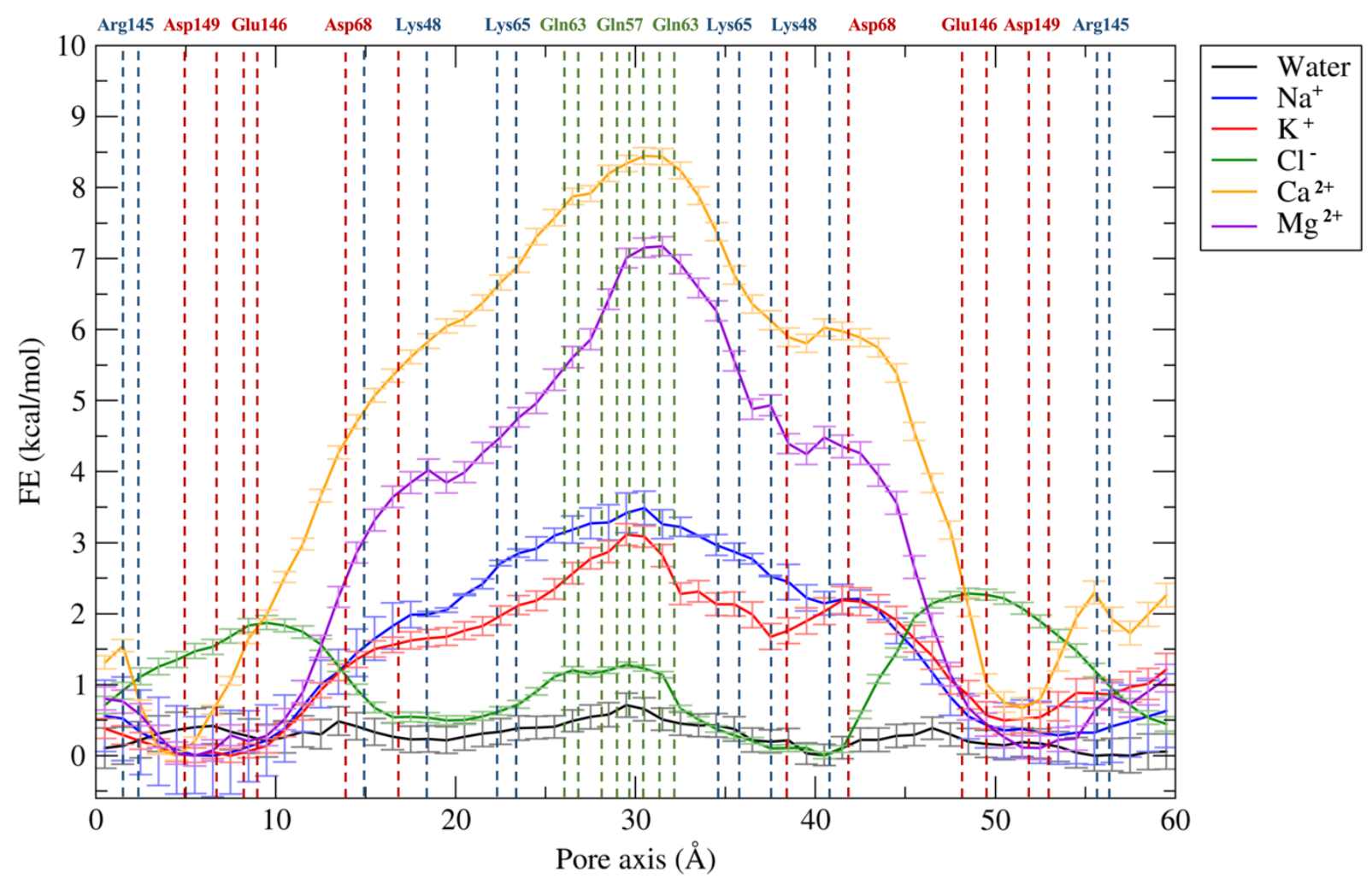

Figure 4. FE profiles for the permeation of water and physiological ions through the Pore I model. Error bars represent the standard deviation of the mean. The position of the most external atoms of the sidechains of relevant residues are indicated as dashed lines.

The Pore I configuration is characterized by an hourglass shape, with a narrow domain in the middle of the structure, where the GIn57 and GIn63 residues from the four protomers form an uncharged cage (Figure 3A). The pore scaffold is completed by positively charged Lys 65 residues, which provide an electrostatic barrier to cations. According to the FE profiles illustrated in Figure 4, the system is permeable to water while the profiles of $\mathrm{Na}^{+}$and $\mathrm{K}^{+}$reveal a FE maximum in the constricted region of $\sim 3 \mathrm{kcal} / \mathrm{mol}$, while for $\mathrm{Ca}^{2+}$ and $\mathrm{Mg}^{2+}$ the barrier is $\sim 7-8 \mathrm{kcal} / \mathrm{mol}$, in agreement with the pivotal role of electrostatics in controlling the paracellular transport ${ }^{33,37,43,49-52}$. Overall, these calculations suggest that the Pore I configuration is an excellent seal against the paracellular transport of cations. The FE profile for the $\mathrm{Cl}^{-}$ion shows barriers of about $2 \mathrm{kcal} / \mathrm{mol}$ symmetrically positioned at the pore entrances, where two identical clusters of negatively charged residues, Asp68, Glu146 and Asp149 (Figure 3A), exert a moderate charge repulsion that limits anion access. Our FE profiles are in overall agreement with those calculated by Irudayanathan et al. ${ }^{37}$ for the same ions permeating through Cldn5 Pore I (there, the authors used the GROMACS code ${ }^{53}$ and the CHARMM $36 \mathrm{~m}$ force field ${ }^{54}$ with virtual site parameters for lipids ${ }^{55}$, and Well-tempered Metadynamics ${ }^{56}$ for enhanced sampling). 


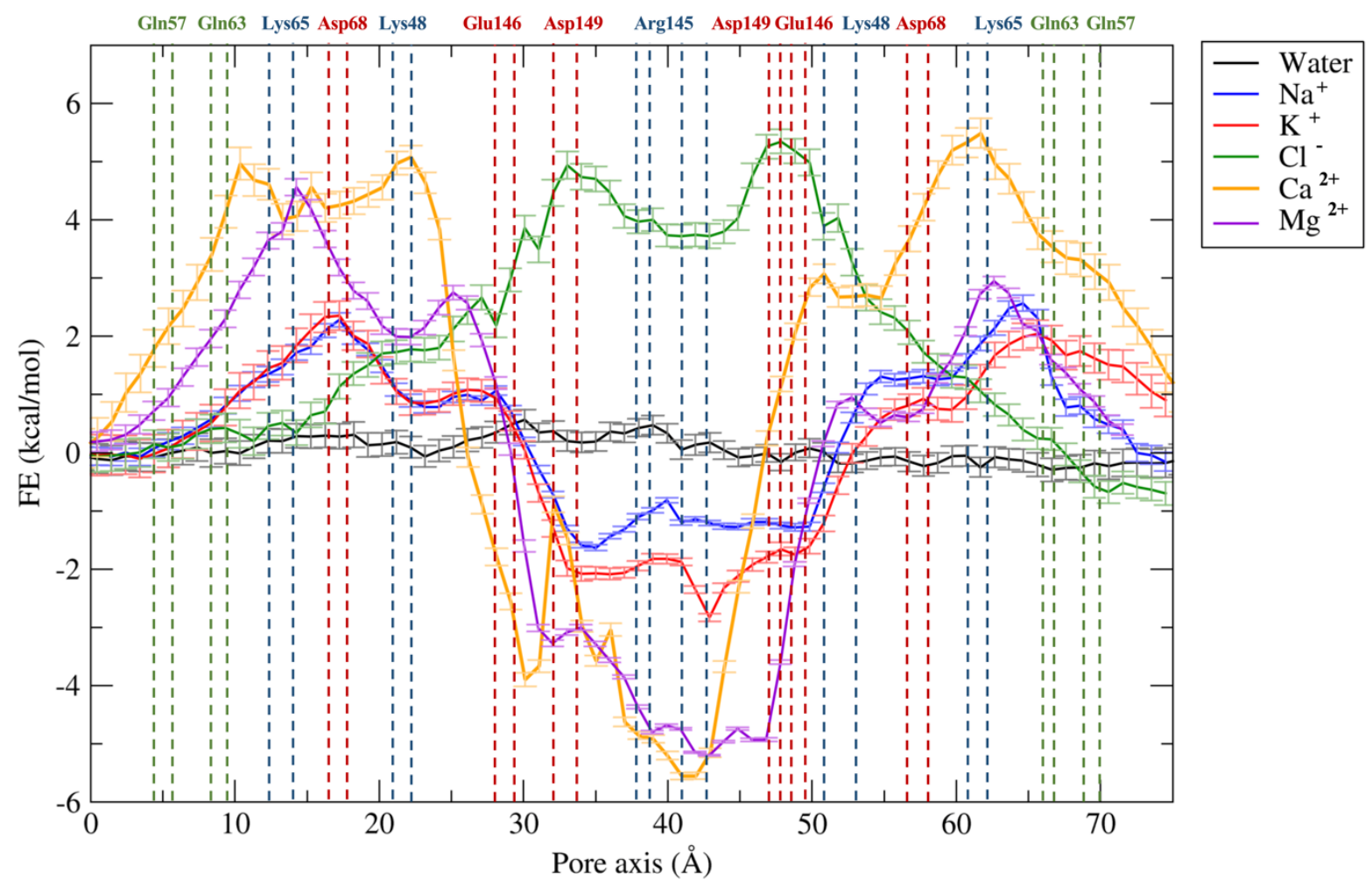

Figure 5. FE profiles for the permeation of water and physiological ions through the Pore II model. Error bars represent standard deviation of the mean. The position of the most external atoms of the sidechains of relevant residues are indicated as dashed lines.

The Pore II system (Figure 5) is also water permeable, but it is characterized by a locally different response to ionic transport. The FE profiles for $\mathrm{Na}^{+}$and $\mathrm{K}^{+}$reveal two FE maxima of $\sim 2 \mathrm{kcal} / \mathrm{mol}$ at the two entrances of the pore cavity, where the positively charged residues Lys65 and Lys48 are located (Figure 3B), together with Asp68. The profiles for $\mathrm{Ca}^{2+}$ and $\mathrm{Mg}^{2+}$ permeations are characterized by higher barriers, up to $5 \mathrm{kcal} / \mathrm{mol}$. Between the two lateral peaks, a minimum for all cations can be found at the center of the structure correlating with a relevant population of negatively charged residue belonging to the four Cldn5 subunits (Glu146 and Asp149). Because of this cluster of residues, the passage of the $\mathrm{Cl}^{-}$ion is prevented by the presence of a FE barrier reaching $5 \mathrm{kcal} / \mathrm{mol}$ that is only slightly damped in the most central region by the four Arg145 residues.

Pore Size and Hydration of $\mathrm{Na}^{+}$and $\mathrm{Cl}^{-}$during Permeation. To further investigate the link between the $\mathrm{FE}$ profiles and the structure of the pores, we investigated the size of the two paracellular cavities, since ion permeation can be influenced by a combination of size and electrostatic effects. We calculated the pore radius profile of both the structures using the HOLE software ${ }^{57,58}$. As shown in Figure 6 , the two models share the same dimension at the two mouths with a diameter of 16-18. . On the contrary, the internal radius profile differs between the two models. Indeed, the Pore I structure is characterized by an hourglass shape, with an inner constriction in the central part of 5-6 A (Figure 6A), where Gln57, Gln63 and Lys65 residues of the four subunits form a narrow cage. On the contrary, the equilibrated Pore II structure has two constrictions of $\sim 6 \AA$ (Figure 6B) in each of the two entrances, where the residues Gln57, Gln63 and Lys65 belonging to two subunits are located. 
A
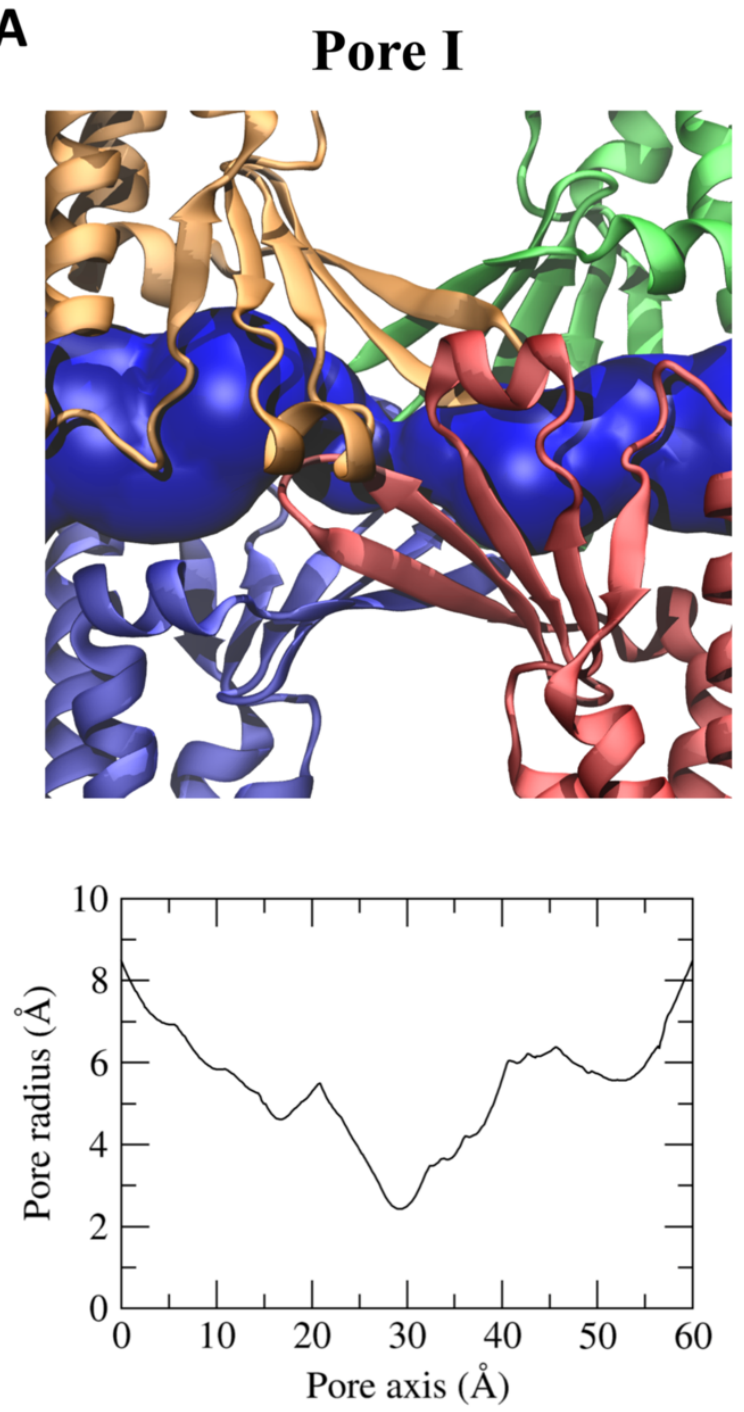

B
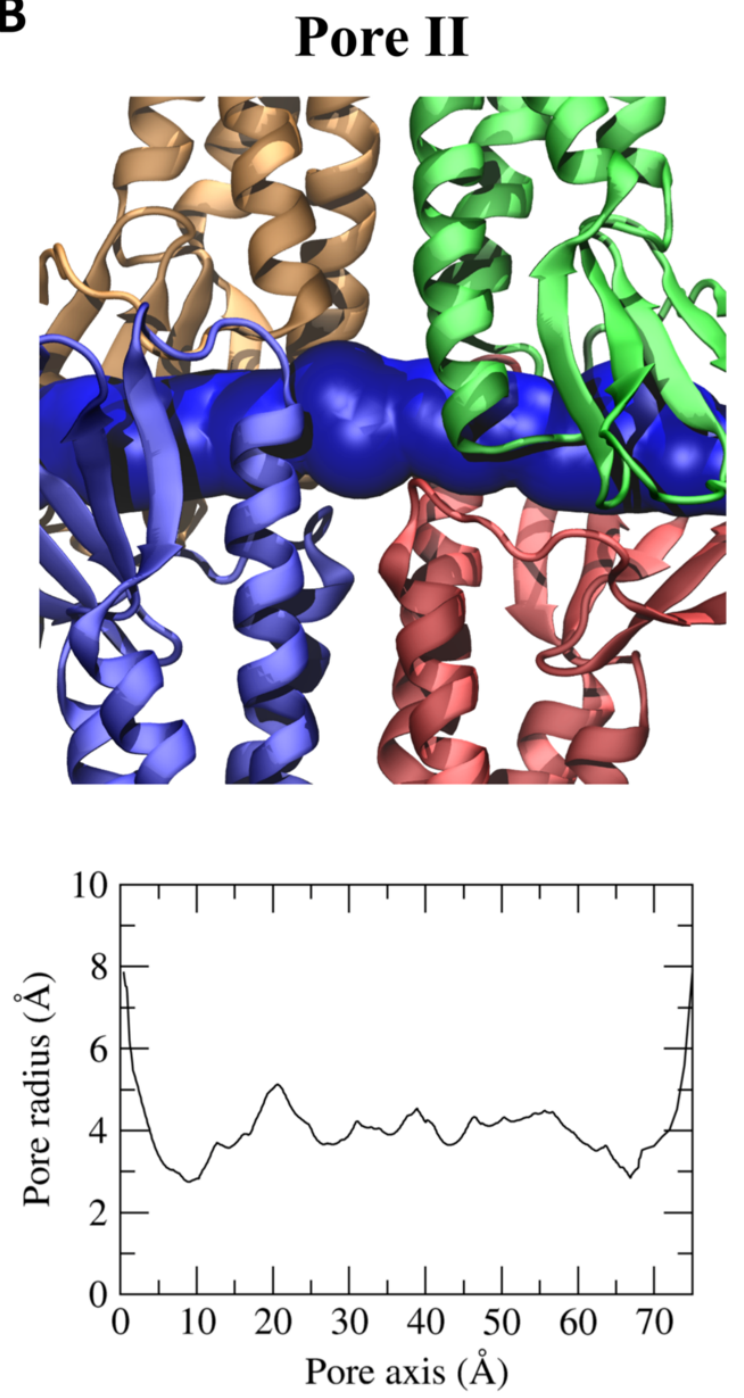

Figure 6. Pore cavities of Pore I (A) and Pore II (B) models. Each protomer is represented in different colors and the pore cavity is shown as a blue surface. In the bottom panels, the pore radius along the pore axis is reported for both the configurations. 

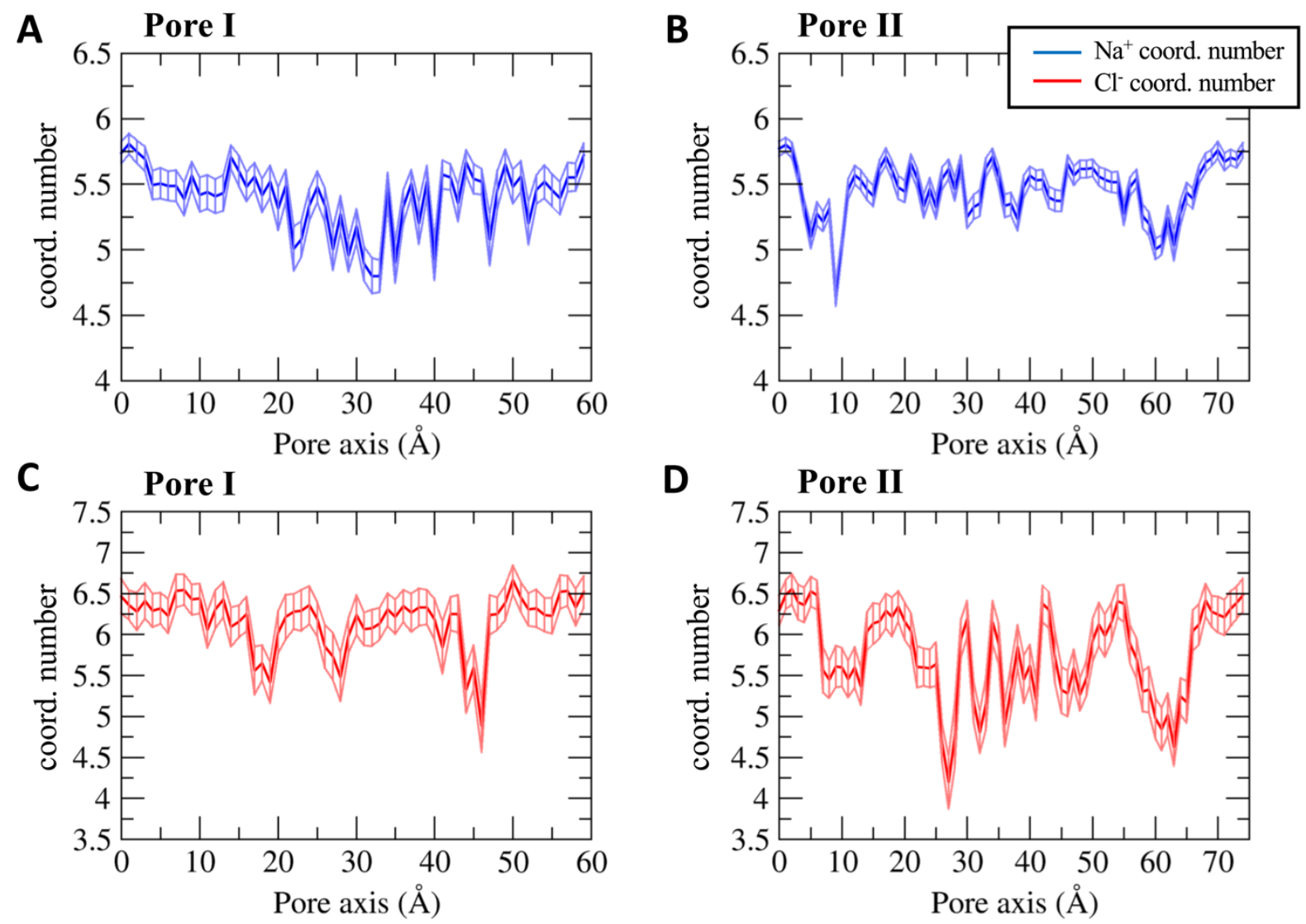

Figure 7. Average number of ion-coordinating water molecules as a function of the pore-axis coordinate for the $\mathrm{Na}^{+}$ion through Pore I (A) and Pore II (B) and for the Cl-ion through Pore I (C) and Pore II (D). Error bars represent the standard deviation of the mean.

We then mapped the hydration pattern of the $\mathrm{Na}^{+}$and $\mathrm{Cl}^{-}$ions during their permeation across the pore cavity (Figure 7). To this aim, we calculated the average number of coordinating oxygen atoms belonging to the water molecules surrounding the ions in each window of the US protocol (see Methods), by adopting a threshold of $3.0 \AA$ for the cation and $3.5 \AA$ for the anion ${ }^{59}$ (the error being computed as standard deviation of the mean).

The ionic hydration profiles correlate with the pore radius of the two structures and with the FE profiles. The $\mathrm{Na}^{+}$and $\mathrm{Cl}^{-}$ions in the solvent bulk are surrounded by $\sim 5.5$ and $\sim 6.5$ water molecules, respectively, in agreement with the values reported in Ref. 59.

The $\mathrm{Na}^{+}$permeating the Pore I cavity (Figure 7A) loses up to one coordinating water molecule in the inner region, where the Pore I exhibits the minimal pore radius (Figure 6A) and the pore-lining neutral GIn57 and Gln63 residues are located. The partial depletion of the solvation sphere while passing through the pore cavity and the unfavorable electrostatic interactions with the positively charged Lys65 residues add up to generate the energetic barrier displayed in Figure 4. Similarly, the cation permeating the Pore II cavity (Figure 7B) shows two minima in the hydration profile at $\sim 10 \AA$ and $\sim 60 \AA$ along the pore axis, which are the narrowest regions of the channel (Figure 6B), where the Lys65 residues are located (Figure 3B). This evidence is consistent with the position of the energetic barriers computed with the US calculations (Figure 5). Between the two peaks, found at the extremities of the cavity, the fluctuations of the average number of coordinating water molecules are smaller, being the pore radius (Figure 6B) slightly larger than the radius of the $\mathrm{Na}^{+}$hydration sphere.

The hydration profile of the $\mathrm{Cl}^{-}$ion across the Pore I (Figure 7C) also correlates with the pore radius and thermodynamics calculations. The FE barriers are found at $\sim 10 \AA$ and $\sim 50 \AA$, corresponding to the positions of Asp149 and Glu146. Here, the pore width allows full hydration of the ion, thus partially screening the interaction with the negatively charged residues. Between these regions, three minima at $\sim 18 \AA, \sim 30 \AA$ and 
bioRxiv preprint doi: https://doi.org/10.1101/2022.03.03.482846; this version posted March 4, 2022. The copyright holder for this preprint (which was not certified by peer review) is the author/funder. All rights reserved. No reuse allowed without permission.

$\sim 45 \AA$ are observed in the hydration pattern, correlating with the position of the pore-lining residues Lys 48 and with the maximal constriction of the cavity.

These findings suggest that the main factor responsible for the formation of the $\mathrm{Cl}^{-}$energetic barriers is the electrostatic repulsion exerted by the negatively charged Asp149 and Glu146 residues, rather than the steric hindrance of the pore. Indeed, in the inner part of the pore, the anion passes through the narrowest segment experiencing a partial dehydration which is not associated to a significant thermodynamic barrier. In contrast, the regions where the FE profiles show the highest barriers to passage of the $\mathrm{Cl}^{-}$are wide enough to accommodate the anion with its entire hydration sphere. The antagonistic contributions of the pore shrinkage and the electrostatics justify the lower entity of the barrier found for the anion $(\sim 2 \mathrm{kcal} / \mathrm{mol})$ with respect to the monovalent cations $(\sim 3-3.5 \mathrm{kcal} / \mathrm{mol})$ in the Pore I configuration.

The hydration scheme of the $\mathrm{Cl}^{-}$ion permeating the Pore II model (Figure 7D) reports relevant fluctuations because of electrostatic interactions with the pore-lining charged residues and steric hindrance in the tight regions, where the contact with polar amino acids takes place. The minima at $\sim 10 \AA$ and $\sim 65 \AA$ correlate with the constrictions of the cavity (Figure 6B). Nevertheless, the central section reveals limited fluctuations in the pore radius, in the same range of the $\mathrm{Cl}^{-}$hydration sphere. For this reason, the major role to the fluctuations in the coordination pattern of the anion is attributed to the interactions of the ion with the porelining residues.

To better investigate the mechanisms of the $\mathrm{Cl}^{-}$hydration profiles within Pore $\mathrm{II}$, we analyzed the changes in the coordinating environment of the anion along the pore axis by mapping the interactions of the ion with the pore-lining positively charged residues and the whole protein. Results are shown in Figure 8.

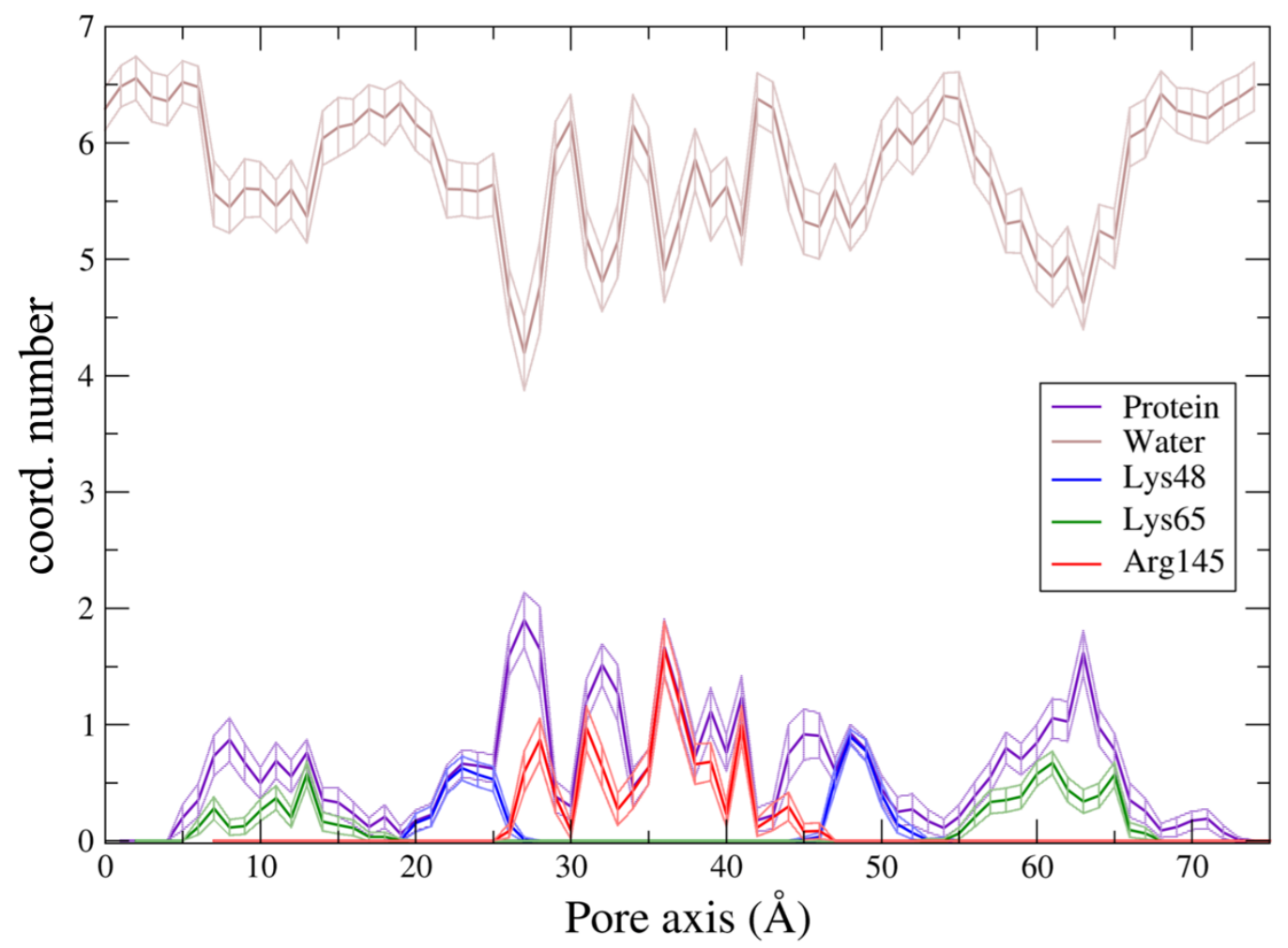

Figure 8. Contributions to the coordination profiles of the $\mathrm{Cl}$ ion in the Pore II cavity.

For this analysis, we used the oxygen atom of the water molecules, the guanidine nitrogen atoms of Arg145, the amine nitrogen atom of both Lys48 and Lys65, the hydroxyl oxygen atom of Ser74 and non-specific heavy atoms of the protein (also including above-mentioned residues). Results show that, in the regions at $\sim 10 \AA$ and $\sim 65 \AA$, the ion interacts not only with Lys 65 , but also with other protein atoms, as a consequence of the constriction of the cavity. In the segments centered at $\sim 22 \AA$ and $\sim 46 \AA$, almost all the interactions with the protein are attributed to Lys 48 , thus revealing a major role of the residue in coordinating the anion to compensate the partial depletion of its solvation sphere. The central segment of the pore axis reveals a fluctuating pattern where the contacts between the anion and the Arg145 residue are predominant. At the 
bioRxiv preprint doi: https://doi.org/10.1101/2022.03.03.482846; this version posted March 4, 2022. The copyright holder for this preprint (which was not certified by peer review) is the author/funder. All rights reserved. No reuse allowed without permission.

sites around $\sim 27 \AA$ and $\sim 45 \AA$, corresponding to a pronounced dehydration of the ion, there is substantial interaction with the protein, albeit not with the Arg145 and Lys48 sidechains.

We next analyzed the time evolution of the hydration pattern in specific windows of the US calculations, related to representative hot-spots in the hydration profile. In particular, we mapped the 20-ns-long trajectories of windows $27,30,61$ and 63 (corresponding to the same positions, expressed in $\AA$, along the pore axis), shown in Figure 9.
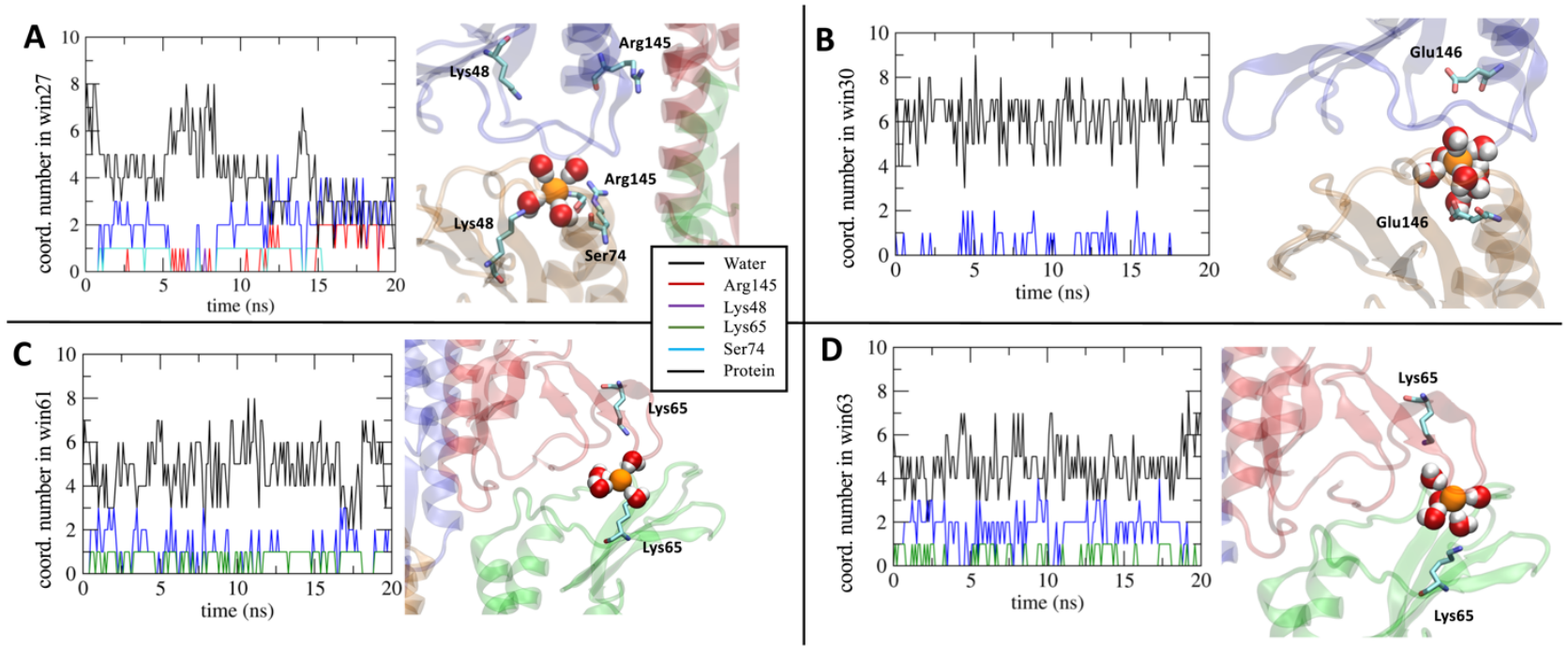

Figure 9. Analysis of the coordination environment of the $\mathrm{Cl}$ ion along the 20-ns-long trajectories in windows (A) $27,(B) 30,(C) 61$ and (D) 63 of the US scheme.

In window 27 (Figure 9A), the $\mathrm{Cl}^{-}$anion loses up to two coordinating water molecules (as evident in Figure 7D). From the analysis of the trajectory, we obtained an average coordination number between the anion and the protein of $1.900 \pm 0.237$, mainly due to the interaction with the positively charged Arg 145 sidechain, the polar Ser74 sidechain and, to a minor extent, the Lys 48 residue. Conversely, in window 30 (Figure 9B), the $\mathrm{Cl}^{-}$is fully hydrated. We calculated the number of contacts with the negatively charged Glu146 and Asp149 and, as expected, none of them was detected along the entire trajectory. The average coordination number with the protein is only $0.295 \pm 0.112$, and it is associated with few contacts between the anion and the neighboring positively-charged (Arg145) or polar (Ser74) residues. Remarkably, this window corresponds to a high-energy region for the $\mathrm{Cl}^{-}$(Figure 5), revealing a major role of the pore-lining negatively charged residues in blocking the anion permeation. Moreover, we investigated the two windows 61 and 63 (Figure 9 C,D), where the $\mathrm{Cl}^{-}$ion experiences a depletion of almost two coordinating water molecules. This region of the cavity is one of the most constricted ones of the Pore II model (Figure 6B) and it also accommodates the Lys65 along with other polar residues. In window 61 (Figure 9C), the anion dehydration is mainly due to the stabilizing electrostatic contact with the positively charged sidechain of the Lys65 residue, with a coordination number of $0.670 \pm 0.100$, which represents almost the totality of the anion - protein interaction. In contrast, in window 63 , the average coordination number of the protein in contact with the $\mathrm{Cl}^{-}$is $1.620 \pm 0.191$, but the contribution of Lys65 is only $0.340 \pm 0.101$, revealing that the coordination sphere of the anion is completed by multiple contacts with different polar residues such as Ser58, GIn 57 and the Gln63. Consequently, in the segment of the Pore II cavity spanning between $55 \AA$ and $70 \AA$ (and, symmetrically, between $5 \AA$ and $20 \AA$ ), the stabilizing electrostatic interaction between the anion and Lys 65 cooperates with the steric occlusion and the subsequent contact with the polar sidechains of other porelining residues to give rise to the marked dehydration reported in Figure 7D. These extreme sections of the pore cavity represent relative low-energy regions to the permeation of the $\mathrm{Cl}^{-}$ions (Figure 5), confirming that the electrostatic interactions between the $\mathrm{Cl}^{-}$and the protein drive the energetics of permeation by compensating the energy cost spent to dehydrate the anion because of the steric occlusion of the cavity.

Discussion. Tight junctions are complex intercellular systems observed in both epithelial and endothelial cells, responsible for the control of the paracellular diffusion processes. Among the various tissue-specific TJs, a major interest is devoted to those located in the BBB. Although it is well known that Cldn 5 proteins are the backbone of $\mathrm{TJ}$ strands of the BBB, we still miss a complete understanding of how they seal the 
paracellular spaces by oligomerization within the same cell (via cis-interactions) and between adjacent cells (via trans-interactions). Here, we studied two different structural models of pore-forming Cldn5 complexes that have been recently introduced ${ }^{40}$. Both models, proposed for Cldn 5 and other Cldns, are consistent with experimental results only in part, so that and their validation has not already been concluded ${ }^{37,40}$. Pore I is in agreement with the structural model proposed by Suzuki and collaborators for the homologous $\mathrm{Cldn} 15^{29}$, in which two protomers belonging to the same cell interact with their ECL1 domains to form a cis-dimer. A couple of these dimers from two opposite cells are then supposed to interact in trans forming a Cldn tetramer characterized by a $\beta$-barrel-like paracellular cavity ${ }^{29}$. After the publication of this model, criticisms were expressed about its validity ${ }^{12}$, regarding steric hindrances at the paracellular interface and inconsistency with the experimentally demonstrated interactions between TM helices of cis-protomers ${ }^{27,28,42}$. On the contrary, in the Pore II structure, Cldn5 cis-dimers are formed via a leucine zipper pattern belonging to TM2/TM3. In particular, TM2/TM3-mediated interactions have been previously described by experiments of Cldn5-based systems ${ }^{28}$. Several successive works revised the two models. Various research groups successfully refined the Pore I configuration for Cldn15 and other $\mathrm{Cldns}^{31-38}$, showing that non overlapping conformations for the ECLs are possible and that the resulting tetramer is stable. Moreover, experimental results based on electron microscopy techniques ${ }^{42,60}$ indicated an arrangement compatible with the Pore I configuration for Cldn3, $\mathrm{Cldn10b}$ and Cldn11. Additional experiments for Cldn3, Cldn10b and Cldn15 showed that the palmitoyl groups are located in proximity of TM domains ${ }^{42,61,62}$, raising the possibility that palmitoylation could perturb the tight packing of cis-interactions at the TM level of Pore II, thus destabilizing the structure. Nevertheless, the multiscale molecular simulations described in Ref. 63 reported that palmitoylation of Cldn 5 enhances the probability of the dimeric arrangement that characterizes Pore II over the other possible cis-configurations occurring at the TM level.

Nevertheless, in the absence of a conclusive experimental result able to discriminate between the two models, both the configurations remain worthy of refinement and study, also in the hypothesis of a heterogeneous distribution of the two pore arrangements. Indeed, computational works indicate the potential coexistence of the two pores in the same TJ strands. Coarse grained MD simulations of selfassembly of Cldn promoters in lipid environment suggest the formation of diversified cis-dimers in the strand, consistent with the dimeric unit that form the two pore configurations $\mathrm{s}^{34,35,40}$. Furthermore, the same authors confirmed the formation of the same dimers using a specific algorithm to obtain millions of Cldn-Cldn conformations and to analyze the amino acid contact maps ${ }^{39,58}$. The results showed the presence of both the Pore I and Pore II structures investigated in this work for Cldn5.

In this framework, we used MD simulations and FE calculations to quantify the thermodynamic features of ionic permeation events through the pore cavities of the two models for Cldn5. The study of ionic processes across biological channels has been an important topic in molecular modeling to look into the details of protein models ${ }^{64}$. In our previous work, we used the same approach to refine the configuration of the Cldn15 pore based on the original structure of Ref. 29. Our efforts contributed to the validation of this structure, confirming the role of the investigation of ion permeation processes for structural validations. In this work, we extended our analysis to the two structural models built for Cldn5 subunits. The HOLE profiles revealed a different pore shape between the two models. The Pore I structure is characterized by an hourglass shape, with the inner constriction in correspondence of residues $\mathrm{G} \ln 57, \mathrm{G} \ln 63$ and Lys65 of the four subunits, measuring 5-6 $\AA$ in diameter. On the contrary, the Pore II structure has two constrictions of $\sim 6 \AA$ in diameter each in proximity of one of the two entrances, where the same residues $G \ln 57, G \ln 63$ and Lys 65 , now from two subunits, are located. Indeed, it is remarkable that, despite the different topology, the internal narrowings are related to the same set of residues. Our FE calculations reveal that both pores are water permeable, a feature not yet fully clarified experimentally, but consistent with previous computational results ${ }^{37,40}$ and as postulated by some authors ${ }^{65}$. On the contrary, the pores show FE barriers to cations. Interestingly, in both the models, the location of the cation barriers corresponds to the narrowest regions. This is in line with the fact that the minimum pore diameters are close to the size of a hydrated $\mathrm{Na}^{+}$ion, and slightly smaller than the diameter of the $\mathrm{Cl}^{-}$hydration shell. This observation pushed us to investigate the details of ion hydration during $\mathrm{Na}^{+}$and $\mathrm{Cl}^{-}$permeation by US simulations. The passage of the $\mathrm{Na}^{+}$ion through the constrictions induces a partial dehydration of its shell. This contributes to generate the FE barrier, together with the unfavorable electrostatic repulsions between the cation and the Lys65 residues of the different Cldn5 subunits. The coupling of steric and electrostatic effects has been already observed in another 
Cldn-based paracellular system ${ }^{33}$ and it is also relevant for the study of other, more conventional, narrow protein channels such as gramicidin ${ }^{66}$ or in the selectivity filter of potassium ${ }^{67,68}$ and sodium ${ }^{69}$ channels. As for the hydration pattern of the $\mathrm{Cl}^{-}$anion, both steric and electrostatic effects induced pronounced fluctuations in the number of water molecules coordinating the anion passing through the pore axis. The smaller solvation energy of $\mathrm{Cl}^{-}$with respect to $\mathrm{Na}^{+}\left(-6.4 \mathrm{kcal} / \mathrm{mol}\right.$ and $-17.2 \mathrm{kcal} / \mathrm{mol}$, respectively $\left.{ }^{70,71}\right)$ provide a more labile coordinating shell to the $\mathrm{Cl}^{-}$ion, and the effects are particularly evident in the regions of the cavities where the pore radius is comparable to the size of the $\mathrm{Cl}^{-}$hydration sphere.

The analysis of the coordinating environment of the anion permeating the Pore II cavity revealed that the energetics of the barriers encountered by the $\mathrm{Cl}^{-}$are mainly driven by the unfavorable electrostatic interactions with the pore-lining acidic residues, while the depletion of the solvation sphere due to steric hindrance is not correlated to high energy regions. Conversely, a stabilizing interacting network with positively charged and polar amino acids able to fill the solvation sphere of the ion is observed in the regions of maximal constriction. For both the models, the FE profiles suggest that the permeation of $\mathrm{Cl}^{-}$is limited by the presence of the negatively charged Asp149 and Glu146 residues. These data indicate the absence of preference for cation versus anion selectivity for both the pore models, in agreement with the well-known characteristics of the $\mathrm{BBB}^{20,39,47}$. Our results complement those exposed for the Pore I in Ref. 37, extending the validation of the two models in terms of ionic permeation features.

\section{CONCLUSIONS}

The BBB plays a pivotal role in controlling the brain homeostasis, thanks to its high selectivity that prevents the passage of potentially dangerous molecules from the blood. As a consequence, it may become a significant obstacle to effective brain drug delivery in the treatment of CNS diseases ${ }^{15-17,20,72-74}$. Strategies are emerging to enhance the BBB permeability by modulating the passive transport across the TJs in the paracellular space between adjacent endothelial cells ${ }^{21-25}$. This approach has already provided promising results from in-vitro experiments of drug-enhancer peptides ${ }^{75,76}$. Although it is well-known that the TJ scaffold is essentially formed by Cldn 5 complexes belonging to the two opposite cells, the fine structural details of the multimeric arrangement are still missing ${ }^{7,12,77}$. Recently, two tetrameric pore-forming models have been introduced after extensive computational investigations based on coarse grained MD simulations ${ }^{40}$. Despite the different topological configurations, both structures, originally named Pore I and Pore II, recapitulate features from experimental results ${ }^{29,30,78}$.

We have refined the structures of the two Cldn5 pore configurations in solvated double-bilayer environment by all-atom MD simulation. Using US we calculated the FE profiles for single-ion translocation across the two pores-We found that both structures fit the typical barrier-like behavior of Cldn 5 in the BBB TJs. The findings illustrated in this work extend our knowledge of Cldn5 TJ structures and, although in the simplest case of single-pore systems, offer a molecular description of Cldn5 role in BBB physiology. Furthermore, by identifying Cldn5 homomeric interaction surfaces in the TJs, our results can contribute to develop experimental strategies to enhance the drug delivery process across the BBB by modulating the paracellular permeability.

\section{METHODS}

\section{Pore I}

The Pore I configuration was assembled with four Cldn5 protomers matching the quaternary structure published by Suzuki et al. ${ }^{29}$. The Cldn5 protomers were modeled from the Cldn 15 homologs using structures from two different works ${ }^{30,32}$, obtaining two putative models for the Pore I. The first model (named Model1) was built starting from the tetrameric configuration of the Cldn15 simulated by Alberini et al. ${ }^{32}$ The second one (named Model2) was assembled starting from the configuration of the Cldn15 pore published by Suzuki et al. ${ }^{29}$. In this case, a single Cldn5 model was built starting from the crystal structure of the mouse Cldn15 protomer (PDB ID: 4P79) ${ }^{30}$. 
Model1. The pore simulated by Alberini et al. ${ }^{32}$ was disassembled in four separated Cldn15 monomers which have adopted slightly different conformations after the simulated trajectories of 250 ns described in Ref. 32 . Each of these four protomers were used for the homology modelling of four Cldn5 monomers via the SWISSMODEL $^{79}$ program. The four raw models of Cldn 5 were then refined with the ModRefiner ${ }^{80}$ server, available at https://zhanggroup.org/ModRefiner . The resulting protomers of Cldn 5 were superimposed on the Cldn15 template ${ }^{32}$ with the UCFS Chimera ${ }^{81}$ tool Matchmaker. Afterwards, the tetrameric system was refined with the GalaxyRefine tool available at the GalaxyWeb server ${ }^{82,83}$ provided by the Seok Lab at http://galaxy.seoklab.org and the highest scoring configuration was selected for MD simulations. The complex was then oriented with the pore axis parallel to the cartesian $y$-axis and embedded in a double bilayer of pure 1-palmitoyl-2-oleoyl-sn-glycero-3-phosphocholine (POPC), solvated with explicit three-point $(\text { TIP3P })^{84}$ water molecules and charge-neutralized with counterions using VMD 1.9.3 ${ }^{85}$. The fullyhydrogenated pdb file of the protein complex was generated with the PDB manipulator tool of CHARMMGUI server 86,87 . Two hexagonal membranes were generated using the membrane builder tool of the same platform ${ }^{87,88}$ and equilibrated separately for $10 \mathrm{~ns}$ with the NAMD 3.0 software ${ }^{89}$ and the CHARMM $36 \mathrm{~m}$ force field ${ }^{54}$ using hexagonal periodic boundary conditions. The final simulation box is a hexagonal prism with a base inscribed in a square of approximately $120.0 \times 120.0 \AA^{2}$ and a height of around $160.0 \AA$. The topology file was built with the psfgen tool of VMD $1.9 .3^{85}$ with the parameters of the CHARMM $36 \mathrm{~m}$ force field ${ }^{54}$ and the four disulfide bridges were preserved between residues Cys54 and Cys64 found in the ECL1 of each protomer.

Model2. The Cldn5 protomer for Model2 was built starting from the crystal structure of the isolated Cldn15 published by Suzuki et al. (PDB ID: 4P79) ${ }^{30}$. The crystal lacks a segment of eight residues $(34-41)$ in the ECL1 that is automatically built by the SWISS-MODEL ${ }^{79}$ engine during the homology modelling of Cldn5. The resulting structure was refined with ModRefiner ${ }^{80}$, consistently with the workflow illustrated for the Model1 and replicated in four identical copies. Following the same protocol illustrated for Model1, the four Cldn5 protomers were assembled to form the tetrameric arrangement named Model2. Analogously, the optimal system was embedded in a hexagonal double membrane bilayer of pure POPC, solvated with water and charge-neutralized with counterions.

Equilibration and unbiased MD simulation. Both Model1 and Model 2 systems contain about 200000 atoms. They were equilibrated with a multi-step protocol where, after a first energy minimization, they were heated up to $310 \mathrm{~K}$ and simulated for $30 \mathrm{~ns}$ with a progressive release of positional restraints on the heavy atoms.

Each model was then simulated for $1 \mu \mathrm{s}$. In order to avoid any rigid body rotational or translational displacement of the protein, the coordinates of the $C \alpha$ atoms of the residues $6,9,20,23,79,82,97,100$, $117,120,138,141,166,169,177,180$, all belonging to the most external residues on the TM $\alpha$ helices, were restrained to their initial values by harmonic potentials. The use of restraints on TM and/or ECLs backbone atoms in the isolated pore conformations can be justified by the fact that this model structure misses the neighbor promoters of the strands, which in the physiological TJ architecture form a scaffold that constraints the pore, limiting the fluctuations of its domains. Notably, in all of our extended MD simulations of Pore I the $\mathrm{ECL}$ domains were stably preserving the $\beta$-barrel structure, and so we limited the restraints to few atoms of TM helices. The systems were simulated in the NPT ensemble at $\mathrm{P}=1 \mathrm{~atm}$ and $\mathrm{T}=310 \mathrm{~K}$, maintained by a Langevin thermostat and Nosè-Hoover Langevin piston ${ }^{90,91}$.

Long range electrostatic interactions were computed using the Particle Mesh Ewald (PME) algorithm ${ }^{92}$. Chemical bonds between hydrogen atoms and protein heavy atoms were constrained with SHAKE ${ }^{93}$ while those of the water molecules were kept fix with SETTLE ${ }^{94}$. The NAMD 3.0 program $^{89}$ with CHARMM36m force field ${ }^{54}$ was used to perform the simulations.

Based on measured pore size and the presence of a hydrogen bond deemed structurally relevant in Refs. 7,12 , we selected Model 2 to represent Pore I and continue with the FE calculations. Comparative analysis of the simulations and details of the choice are reported in the Supplementary Information file. 


\section{Pore II}

The Pore II configuration was described in Ref. 40. In this architecture, the cis-interface originates from to the interaction of two neighboring protomers at the level of the TM helices arranging in a leucine zipper composed by the residues Leu83, Leu90, Leu124 and Leu131 on the TM2 and TM3, supported by two homophilic $\pi$ - $\pi$-interactions between Phe127 and Trp138 on the opposing TM domains (Figure 1B).

To build this structure, we first simulated a Cldn5 protomer, again homology-modeled from the Cldn15 template. The protein was embedded in a rectangular pure POPC membrane bilayer and equilibrated with a 110-ns-long all-atom MD simulation in explicit solvent. The trajectory was analyzed to assess the structural stability of the protein (see the Supplementary Information file).

An equilibrated configuration of the Cldn 5 protomer was extracted from the trajectory and used to reproduce the cis-interface first via a docking protocol. The leucine zipper TM interaction between two copies of the protein was predicted by the MEMDOCK tool ${ }^{95}$, which includes a specific algorithm for docking $\alpha$ - helical membrane proteins. The dimer selected by MEMDOCK ${ }^{95}$ was further refined with the DOCKING2 tool of Rosie, a Rosetta online server ${ }^{96-98}$, and the structure finely reproducing the leucine zipper was embedded in a pure POPC membrane, solvated with explicit water and equilibrated with 100 ns of all-atom MD simulation in presence of charge-neutralizing counterions. The final dimer complex was replicated and the two copies were used to assemble the Pore II configuration with a further docking approach. Following the protocol suggested in Ref. 40, the Pore II complex was generated adopting the ClusPro docking algorithm ${ }^{99-103}$ to reproduce the trans-interactions occurring between two opposing dimers at the level of the paracellular domains. Afterwards, the tetrameric structure was refined using the algorithm of the GalaxyRefine tool ${ }^{82,83}$, oriented with the pore axis parallel to the cartesian $y$-axis and embedded in a hexagonal double bilayer of pure POPC, solvated with water and charge-neutralized with counterions. The topology file was built with the psfgen tool of VMD $1.9 .3^{85}$ with CHARMM $36 \mathrm{~m}$ parameters ${ }^{54}$ and the four disulfide bridges were preserved between residues Cys54 and Cys64 found in the ECL1 of each protomer.

Equilibration and unbiased MD simulation. The Pore Il simulation set-up ( 200000 atoms) followed the same protocol described for the two putative models of Pore I. Additionally, further harmonic restraints were applied on the $C \alpha$ atoms of the residues $11,14,25,28,78,81,99,102,116,119,143,146,166,169,183$, 186 in the ECLs of the protomers.

\section{PORE SIZE ANALYSIS}

The size of the paracellular pores were monitored along the trajectory with the HOLE program ${ }^{57,58}$. The algorithm maps the radius of a protein cavity along a given axis (here, the $y$-axis) by fitting a spherical probe with the Van der Waals radii of the pore-lining atoms. For the two models of Pore I, a $15 \AA$ threshold was chosen for the pore radius and representative structures spaced by $10 \mathrm{~ns}$ along the production trajectory were selected and analyzed (see the Supplementary Information file).

\section{FREE ENERGY CALCULATIONS}

The free energy (FE) profiles for the permeation of a water molecule and single ions $\left(\mathrm{Na}^{+}, \mathrm{K}^{+}, \mathrm{Cl}^{-}, \mathrm{Mg}^{2+}, \mathrm{Ca}^{2+}\right)$ were calculated using the Umbrella Sampling (US) method $^{104}$. A restraining term is added to the MD potential to confine a collective variable ( $\mathrm{CV}$, function of the cartesian coordinates of the system) in selected regions, named windows, allowing proper sampling even in high-energy regions of the landscape. As CV, we chose the coordinate of the tagged permeating ion along the pore axis, previously aligned with the cartesian $y$-axis, and the restraining potential $V_{i}(y)$ in each window $i$ is:

$$
V_{i}(y)=\frac{1}{2} k\left(y-y_{i}^{0}\right)^{2}
$$

where $y_{i}^{0}$ indicates the value in $\AA$ at which the $\mathrm{CV}$ is restrained in the window (called center) and $k$ is a constant that is appropriately chosen in order to ensure a sufficient overlap of the CV distributions from adjacent windows (in this work, we used $k=2.0 \mathrm{kcal} /\left(\mathrm{mol} \AA^{2}\right)$ for all simulations). In each window, the displacement of the ion orthogonal to the pore axis is confined within a disk of radius $r_{0}+\delta$, where $r_{0}$ is the pore radius as determined by the HOLE program ${ }^{57,58}$ and $\delta=2 \AA$. The equilibrated conformation of the system was used as starting structure of all US windows, and the ion was manually positioned at each center $y_{i}^{0}$. 
The Pore I cavity was split into 60 windows. Each window was minimized and simulated for 16 ns with the same set up described for the standard MD simulation, adding the bias to the force field ${ }^{105}$ via the colvars module ${ }^{106}$. Positional restraints on selected $\mathrm{C} \alpha$ atoms were applied as described for the unbiased simulations. The first ns of production was excluded from the statistics. Due to the elongated shape of the Pore II cavity, 75 windows were required to sample the entire cavity. The simulation followed the same protocol adopted for the Pore I, except that 20 ns of production per window were carried out in order to achieve a proper convergence.

The full FE profiles are obtained by combining the CV distributions of all windows using the weighted histogram analysis method (WHAM) ${ }^{48,107,108}$. We employed the code from the Grossfield group available at http://membrane.urmc.rochester.edu/content/wham. The block error analysis was also implemented to the calculated FE profiles (see the Supplementary Information file).

\section{Corresponding Authors}

Fabio Benfenati. Email: fabio.benfenati@iit.it

Luca Maragliano. Email: luca.maragliano@iit.it

\section{Author Contributions}

"Alessandro Berselli and "Giulio Alberini equally contributed to perform the simulations, to analyze the data, to discuss the results and to write the manuscript. Luca Maragliano and Fabio Benfenati supervised the entire research, discussed the results and revised the manuscript.

\section{Supporting information}

All-atom MD simulation and analysis of the Pore I models, Free Energy profiles with the block error analysis and all-atom MD simulation and analysis of the Cldn5 protomer are provided in the Supporting Information file.

\section{Acknowledgments}

We thank Jörg Piontek and Matteo Ceccarelli for useful discussions; Sergio Decherchi, Diego Moruzzo and Andrea L. Benfenati for valuable help. Computing time allocations were granted by the CINECA supercomputing center under the ISCRA initiative. We also gratefully acknowledge the HPC infrastructure and the Support Team at Fondazione Istituto Italiano di Tecnologia. The research was supported by IRCCS Ospedale Policlinico San Martino (Ricerca Corrente and 5x1000 grants to FB and LM) and by Telethon/Glut1 Onlus Foundations (seed project 1754 to FB).

\section{Notes}

The authors declare no competing financial interest.

\section{REFERENCES}

(1) Furuse, M.; Sasaki, H.; Fujimoto, K.; Tsukita, S. A Single Gene Product, Claudin-1 or -2, Reconstitutes Tight Junction Strands and Recruits Occludin in Fibroblasts. J. Cell Biol. 1998, 143 (2), 391-401. https://doi.org/10.1083/jcb.143.2.391.

(2) Morita, K.; Sasaki, H.; Furuse, M.; Tsukita, S. Endothelial Claudin. J. Cell Biol. 1999, 147 (1), 185-194.

(3) Anderson, J. M. Molecular Structure of Tight Junctions and Their Role in Epithelial Transport. News Physiol. Sci. Int. J. Physiol. Prod. Jointly Int. Union Physiol. Sci. Am. Physiol. Soc. 2001, 16, 126-130. https://doi.org/10.1152/physiologyonline.2001.16.3.126.

(4) Farquhar, M. G.; Palade, G. E. Junctional Complexes in Various Epithelia. J. Cell Biol. 1963, 17 (2), 375412.

(5) Gumbiner, B. Structure, Biochemistry, and Assembly of Epithelial Tight Junctions. Am. J. Physiol.-Cell Physiol. 1987, 253 (6), C749-C758. https://doi.org/10.1152/ajpcell.1987.253.6.C749.

(6) Krause, G.; Winkler, L.; Mueller, S. L.; Haseloff, R. F.; Piontek, J.; Blasig, I. E. Structure and Function of Claudins. Biochim. Biophys. Acta BBA - Biomembr. 2008, 1778 (3), 631-645. https://doi.org/10.1016/j.bbamem.2007.10.018. 
bioRxiv preprint doi: https://doi.org/10.1101/2022.03.03.482846; this version posted March 4, 2022. The copyright holder for this preprint (which was not certified by peer review) is the author/funder. All rights reserved. No reuse allowed without permission.

(7) Piontek, J.; Krug, S. M.; Protze, J.; Krause, G.; Fromm, M. Molecular Architecture and Assembly of the Tight Junction Backbone. Biochim. Biophys. Acta BBA - Biomembr. 2020, 1862 (7), 183279. https://doi.org/10.1016/j.bbamem.2020.183279.

(8) Claude, P.; Goodenough, D. A. Fracture Faces of Zonulae Occludentes from "Tight" and "Leaky" Epithelia. J. Cell Biol. 1973, 58 (2), 390-400.

(9) Claude, P. Morphological Factors Influencing Transepithelial Permeability: A Model for the Resistance of TheZonula Occludens. J. Membr. Biol. 1978, 39 (2), 219-232. https://doi.org/10.1007/BF01870332.

(10) Bonetta, L. Endothelial Tight Junctions Form the Blood-Brain Barrier. J. Cell Biol. 2005, 169 (3), 378379. https://doi.org/10.1083/jcb1693fta1.

(11) Günzel, D.; Yu, A. S. L. Claudins and the Modulation of Tight Junction Permeability. Physiol. Rev. 2013, 93 (2), 525-569. https://doi.org/10.1152/physrev.00019.2012.

(12) Krause, G.; Protze, J.; Piontek, J. Assembly and Function of Claudins: Structure-Function Relationships Based on Homology Models and Crystal Structures. Semin. Cell Dev. Biol. 2015, 42, 3-12. https://doi.org/10.1016/j.semcdb.2015.04.010.

(13) Piontek, J.; Winkler, L.; Wolburg, H.; Müller, S. L.; Zuleger, N.; Piehl, C.; Wiesner, B.; Krause, G.; Blasig, I. E. Formation of Tight Junction: Determinants of Homophilic Interaction between Classic Claudins. FASEB J. Off. Publ. Fed. Am. Soc. Exp. Biol. 2008, 22 (1), 146-158. https://doi.org/10.1096/fj.07-8319com.

(14) Angelow, S.; Ahlstrom, R.; Yu, A. S. L. Biology of Claudins. Am. J. Physiol. Renal Physiol. 2008, 295 (4), F867-876. https://doi.org/10.1152/ajprenal.90264.2008.

(15) Powell, D. W. Barrier Function of Epithelia. Am. J. Physiol. 1981, 241 (4), G275-288. https://doi.org/10.1152/ajpgi.1981.241.4.G275.

(16) Tang, V. W.; Goodenough, D. A. Paracellular Ion Channel at the Tight Junction. Biophys. J. 2003, 84 (3), 1660-1673. https://doi.org/10.1016/S0006-3495(03)74975-3.

(17) Bauer, H.-C.; Krizbai, I. A.; Bauer, H.; Traweger, A. "You Shall Not Pass"-Tight Junctions of the Blood Brain Barrier. Front. Neurosci. 2014, 8, 392. https://doi.org/10.3389/fnins.2014.00392.

(18) Abbott, N. J.; Patabendige, A. A. K.; Dolman, D. E. M.; Yusof, S. R.; Begley, D. J. Structure and Function of the Blood-Brain Barrier. Neurobiol. Dis. 2010, 37 (1), 13-25. https://doi.org/10.1016/j.nbd.2009.07.030.

(19) Daneman, R.; Prat, A. The Blood-Brain Barrier. Cold Spring Harb. Perspect. Biol. 2015, 7 (1), a020412. https://doi.org/10.1101/cshperspect.a020412.

(20) Pardridge, W. M. The Blood-Brain Barrier: Bottleneck in Brain Drug Development. NeuroRx J. Am. Soc. Exp. Neurother. 2005, 2 (1), 3-14. https://doi.org/10.1602/neurorx.2.1.3.

(21) Hashimoto, Y.; Campbell, M. Tight Junction Modulation at the Blood-Brain Barrier: Current and Future Perspectives. Biochim. Biophys. Acta BBA - Biomembr. 2020, 1862 (9), 183298. https://doi.org/10.1016/j.bbamem.2020.183298.

(22) Staat, C.; Coisne, C.; Dabrowski, S.; Stamatovic, S. M.; Andjelkovic, A. V.; Wolburg, H.; Engelhardt, B.; Blasig, I. E. Mode of Action of Claudin Peptidomimetics in the Transient Opening of Cellular Tight Junction Barriers. Biomaterials 2015, 54, 9-20. https://doi.org/10.1016/j.biomaterials.2015.03.007.

(23) Dithmer, S.; Staat, C.; Müller, C.; Ku, M.-C.; Pohlmann, A.; Niendorf, T.; Gehne, N.; Fallier-Becker, P.; Kittel, Á.; Walter, F. R.; Veszelka, S.; Deli, M. A.; Blasig, R.; Haseloff, R. F.; Blasig, I. E.; Winkler, L. Claudin Peptidomimetics Modulate Tissue Barriers for Enhanced Drug Delivery. Ann. N. Y. Acad. Sci. 2017, 1397 (1), 169-184. https://doi.org/10.1111/nyas.13359.

(24) Neuhaus, W.; Piontek, A.; Protze, J.; Eichner, M.; Mahringer, A.; Subileau, E.-A.; Lee, I.-F. M.; Schulzke, J. D.; Krause, G.; Piontek, J. Reversible Opening of the Blood-Brain Barrier by Claudin-5-Binding Variants of Clostridium Perfringens Enterotoxin's Claudin-Binding Domain. Biomaterials 2018, 161, 129-143. https://doi.org/10.1016/j.biomaterials.2018.01.028.

(25) Zwanziger, D.; Hackel, D.; Staat, C.; Böcker, A.; Brack, A.; Beyermann, M.; Rittner, H.; Blasig, I. E. A Peptidomimetic Tight Junction Modulator to Improve Regional Analgesia. Mol. Pharm. 2012, 9 (6), 17851794. https://doi.org/10.1021/mp3000937.

(26) Angelow, S.; Yu, A. S. L. Structure-Function Studies of Claudin Extracellular Domains by CysteineScanning Mutagenesis. J. Biol. Chem. 2009, 284 (42), 29205-29217. https://doi.org/10.1074/jbc.M109.043752.

(27) Van Itallie, C. M.; Mitic, L. L.; Anderson, J. M. Claudin-2 Forms Homodimers and Is a Component of a High Molecular Weight Protein Complex. J. Biol. Chem. 2011, 286 (5), 3442-3450. 
bioRxiv preprint doi: https://doi.org/10.1101/2022.03.03.482846; this version posted March 4, 2022. The copyright holder for this preprint (which was not certified by peer review) is the author/funder. All rights reserved. No reuse allowed without permission.

https://doi.org/10.1074/jbc.M110.195578.

(28) Rossa, J.; Ploeger, C.; Vorreiter, F.; Saleh, T.; Protze, J.; Günzel, D.; Wolburg, H.; Krause, G.; Piontek, J. Claudin-3 and Claudin-5 Protein Folding and Assembly into the Tight Junction Are Controlled by NonConserved Residues in the Transmembrane 3 (TM3) and Extracellular Loop 2 (ECL2) Segments. J. Biol. Chem. 2014, 289 (11), 7641-7653. https://doi.org/10.1074/jbc.M113.531012.

(29) Suzuki, H.; Tani, K.; Tamura, A.; Tsukita, S.; Fujiyoshi, Y. Model for the Architecture of Claudin-Based Paracellular Ion Channels through Tight Junctions. J. Mol. Biol. 2015, 427 (2), 291-297. https://doi.org/10.1016/j.jmb.2014.10.020.

(30) Suzuki, H.; Nishizawa, T.; Tani, K.; Yamazaki, Y.; Tamura, A.; Ishitani, R.; Dohmae, N.; Tsukita, S.; Nureki, O.; Fujiyoshi, Y. Crystal Structure of a Claudin Provides Insight into the Architecture of Tight Junctions. Science 2014, 344 (6181), 304-307. https://doi.org/10.1126/science.1248571.

(31) Fuladi, S.; Jannat, R.-W.; Shen, L.; Weber, C. R.; Khalili-Araghi, F. Computational Modeling of Claudin Structure and Function. Int. J. Mol. Sci. 2020, 21 (3), 742. https://doi.org/10.3390/ijms21030742.

(32) Alberini, G.; Benfenati, F.; Maragliano, L. A Refined Model of Claudin-15 Tight Junction Paracellular Architecture by Molecular Dynamics Simulations. PLOS ONE 2017, 12 (9), e0184190. https://doi.org/10.1371/journal.pone.0184190.

(33) Alberini, G.; Benfenati, F.; Maragliano, L. Molecular Dynamics Simulations of Ion Selectivity in a Claudin-15 Paracellular Channel. J. Phys. Chem. B 2018, 122 (48), 10783-10792. https://doi.org/10.1021/acs.jpcb.8b06484.

(34) Irudayanathan, F. J.; Trasatti, J. P.; Karande, P.; Nangia, S. Molecular Architecture of the Blood Brain Barrier Tight Junction Proteins--A Synergistic Computational and In Vitro Approach. J. Phys. Chem. B 2016, 120 (1), 77-88. https://doi.org/10.1021/acs.jpcb.5b09977.

(35) Irudayanathan, F. J.; Wang, X.; Wang, N.; Willsey, S. R.; Seddon, I. A.; Nangia, S. Self-Assembly Simulations of Classic Claudins-Insights into the Pore Structure, Selectivity, and Higher Order Complexes. J. Phys. Chem. B 2018, 122 (30), 7463-7474. https://doi.org/10.1021/acs.jpcb.8b03842.

(36) Samanta, P.; Wang, Y.; Fuladi, S.; Zou, J.; Li, Y.; Shen, L.; Weber, C.; Khalili-Araghi, F. Molecular Determination of Claudin-15 Organization and Channel Selectivity. J. Gen. Physiol. 2018, 150 (7), 949-968. https://doi.org/10.1085/jgp.201711868.

(37) Irudayanathan, F. J.; Nangia, S. Paracellular Gatekeeping: What Does It Take for an Ion to Pass Through a Tight Junction Pore? Langmuir 2020, 36 (24), 6757-6764. https://doi.org/10.1021/acs.langmuir.0c00877.

(38) Zhao, J.; Krystofiak, E. S.; Ballesteros, A.; Cui, R.; Van Itallie, C. M.; Anderson, J. M.; Fenollar-Ferrer, C.; Kachar, B. Multiple Claudin-Claudin Cis Interfaces Are Required for Tight Junction Strand Formation and Inherent Flexibility. Commun. Biol. 2018, 1, 50. https://doi.org/10.1038/s42003-018-0051-5.

(39) Wen, H.; Watry, D. D.; Marcondes, M. C. G.; Fox, H. S. Selective Decrease in Paracellular Conductance of Tight Junctions: Role of the First Extracellular Domain of Claudin-5. Mol. Cell. Biol. 2004, 24 (19), 84088417. https://doi.org/10.1128/MCB.24.19.8408-8417.2004.

(40) Irudayanathan, F. J.; Wang, N.; Wang, X.; Nangia, S. Architecture of the Paracellular Channels Formed by Claudins of the Blood-Brain Barrier Tight Junctions. Ann. N. Y. Acad. Sci. 2017, 1405 (1), 131-146. https://doi.org/10.1111/nyas.13378.

(41) Rajagopal, N.; Durand, A. J.; Nangia, S. Predicting Selectivity of Paracellular Pores for Biomimetic Applications. Mol. Syst. Des. Eng. 2020, 5 (3), 686-696. https://doi.org/10.1039/C9ME00177H.

(42) Hempel, C.; Protze, J.; Altun, E.; Riebe, B.; Piontek, A.; Fromm, A.; Lee, I. M.; Saleh, T.; Günzel, D.; Krause, G.; Piontek, J. Assembly of Tight Junction Strands: Claudin-10b and Claudin-3 Form Homo-Tetrameric Building Blocks That Polymerise in a Channel-Independent Manner. J. Mol. Biol. 2020, 432 (7), 2405-2427. https://doi.org/10.1016/j.jmb.2020.02.034.

(43) Yu, A. S. L.; Cheng, M. H.; Angelow, S.; Günzel, D.; Kanzawa, S. A.; Schneeberger, E. E.; Fromm, M.; Coalson, R. D. Molecular Basis for Cation Selectivity in Claudin-2-Based Paracellular Pores: Identification of an Electrostatic Interaction Site. J. Gen. Physiol. 2008, 133 (1), 111-127. https://doi.org/10.1085/jgp.200810154.

(44) Günzel, D.; Fromm, M. Claudins and Other Tight Junction Proteins. Compr. Physiol. 2012, 2 (3), 18191852. https://doi.org/10.1002/cphy.c110045.

(45) Colegio, O. R.; Itallie, C. V.; Rahner, C.; Anderson, J. M. Claudin Extracellular Domains Determine 
bioRxiv preprint doi: https://doi.org/10.1101/2022.03.03.482846; this version posted March 4, 2022. The copyright holder for this preprint (which was not certified by peer review) is the author/funder. All rights reserved. No reuse allowed without permission.

Paracellular Charge Selectivity and Resistance but Not Tight Junction Fibril Architecture. Am. J. Physiol.-Cell Physiol. 2003, 284 (6), C1346-C1354. https://doi.org/10.1152/ajpcell.00547.2002.

(46) Van Itallie, C. M.; Anderson, J. M. Claudins and Epithelial Paracellular Transport. Annu. Rev. Physiol. 2006, 68, 403-429. https://doi.org/10.1146/annurev.physiol.68.040104.131404.

(47) Nitta, T.; Hata, M.; Gotoh, S.; Seo, Y.; Sasaki, H.; Hashimoto, N.; Furuse, M.; Tsukita, S. Size-Selective Loosening of the Blood-Brain Barrier in Claudin-5-Deficient Mice. J. Cell Biol. 2003, 161 (3), 653-660. https://doi.org/10.1083/jcb.200302070.

(48) Kumar, S.; Rosenberg, J. M.; Bouzida, D.; Swendsen, R. H.; Kollman, P. A. THE Weighted Histogram Analysis Method for Free-Energy Calculations on Biomolecules. I. The Method. J. Comput. Chem. 1992, 13 (8), 1011-1021. https://doi.org/10.1002/jcc.540130812.

(49) Krug, S. M.; Günzel, D.; Conrad, M. P.; Lee, I.-F. M.; Amasheh, S.; Fromm, M.; Yu, A. S. L. ChargeSelective Claudin Channels. Ann. N. Y. Acad. Sci. 2012, 1257 (1), 20-28. https://doi.org/10.1111/j.17496632.2012.06555.x.

(50) Hou, J.; Renigunta, A.; Yang, J.; Waldegger, S. Claudin-4 Forms Paracellular Chloride Channel in the Kidney and Requires Claudin-8 for Tight Junction Localization. Proc. Natl. Acad. Sci. 2010, 107 (42), 1801018015. https://doi.org/10.1073/pnas.1009399107.

(51) Van Itallie, C. M.; Fanning, A. S.; Anderson, J. M. Reversal of Charge Selectivity in Cation or AnionSelective Epithelial Lines by Expression of Different Claudins. Am. J. Physiol. Renal Physiol. 2003, 285 (6), F1078-1084. https://doi.org/10.1152/ajprenal.00116.2003.

(52) Colegio, O. R.; Van Itallie, C. M.; McCrea, H. J.; Rahner, C.; Anderson, J. M. Claudins Create ChargeSelective Channels in the Paracellular Pathway between Epithelial Cells. Am. J. Physiol.-Cell Physiol. 2002, 283 (1), C142-C147. https://doi.org/10.1152/ajpcell.00038.2002.

(53) Abraham, M. J.; Murtola, T.; Schulz, R.; Páll, S.; Smith, J. C.; Hess, B.; Lindahl, E. GROMACS: High Performance Molecular Simulations through Multi-Level Parallelism from Laptops to Supercomputers. SoftwareX 2015, 1, 19-25. https://doi.org/10.1016/j.softx.2015.06.001.

(54) Huang, J.; Rauscher, S.; Nawrocki, G.; Ran, T.; Feig, M.; de Groot, B. L.; Grubmüller, H.; MacKerell, A. D. CHARMM36m: An Improved Force Field for Folded and Intrinsically Disordered Proteins. Nat. Methods 2017, 14 (1), 71-73. https://doi.org/10.1038/nmeth.4067.

(55) Loubet, B.; Kopec, W.; Khandelia, H. Accelerating All-Atom MD Simulations of Lipids Using a Modified Virtual-Sites Technique. J. Chem. Theory Comput. 2014, 10 (12), 5690-5695. https://doi.org/10.1021/ct500100f.

(56) Barducci, A.; Bussi, G.; Parrinello, M. Well-Tempered Metadynamics: A Smoothly Converging and Tunable Free-Energy Method. Phys. Rev. Lett. 2008, 100 (2), 020603. https://doi.org/10.1103/PhysRevLett.100.020603.

(57) Smart, O. S.; Breed, J.; Smith, G. R.; Sansom, M. S. A Novel Method for Structure-Based Prediction of Ion Channel Conductance Properties. Biophys. J. 1997, 72 (3), 1109-1126. https://doi.org/10.1016/S00063495(97)78760-5.

(58) Smart, O. S.; Neduvelil, J. G.; Wang, X.; Wallace, B. A.; Sansom, M. S. P. HOLE: A Program for the Analysis of the Pore Dimensions of Ion Channel Structural Models. J. Mol. Graph. 1996, 14 (6), 354-360. https://doi.org/10.1016/S0263-7855(97)00009-X.

(59) Lev, B.; Roux, B.; Noskov, S. Yu. Relative Free Energies for Hydration of Monovalent lons from QM and QM/MM Simulations. J. Chem. Theory Comput. 2013, 9 (9), 4165-4175. https://doi.org/10.1021/ct400296w.

(60) Krystofiak, E. S.; Heymann, J. B.; Kachar, B. Carbon Replicas Reveal Double Stranded Structure of Tight Junctions in Phase-Contrast Electron Microscopy. Commun. Biol. 2019, 2, 98. https://doi.org/10.1038/s42003-019-0319-4.

(61) Rodenburg, R. N. P.; Snijder, J.; van de Waterbeemd, M.; Schouten, A.; Granneman, J.; Heck, A. J. R.; Gros, P. Stochastic Palmitoylation of Accessible Cysteines in Membrane Proteins Revealed by Native Mass Spectrometry. Nat. Commun. 2017, 8 (1), 1280. https://doi.org/10.1038/s41467-017-01461-z.

(62) Van Itallie, C. M.; Gambling, T. M.; Carson, J. L.; Anderson, J. M. Palmitoylation of Claudins Is Required for Efficient Tight-Junction Localization. J. Cell Sci. 2005, 118 (Pt 7), 1427-1436. https://doi.org/10.1242/jcs.01735.

(63) Rajagopal, N.; Irudayanathan, F. J.; Nangia, S. Palmitoylation of Claudin-5 Proteins Influences Their 
bioRxiv preprint doi: https://doi.org/10.1101/2022.03.03.482846; this version posted March 4, 2022. The copyright holder for this preprint (which was not certified by peer review) is the author/funder. All rights reserved. No reuse allowed without permission.

Lipid Domain Affinity and Tight Junction Assembly at the Blood-Brain Barrier Interface. J. Phys. Chem. B 2019, 123 (5), 983-993. https://doi.org/10.1021/acs.jpcb.8b09535.

(64) Khalili-Araghi, F.; Tajkhorshid, E.; Roux, B.; Schulten, K. Molecular Dynamics Investigation of the $\omega$ Current in the Kv1.2 Voltage Sensor Domains. Biophys. J. 2012, 102 (2), 258-267. https://doi.org/10.1016/j.bpj.2011.10.057.

(65) Fisher, D.; Mentor, S. Are Claudin-5 Tight-Junction Proteins in the Blood-Brain Barrier Porous? Neural Regen. Res. 2020, 15 (10), 1838-1839. https://doi.org/10.4103/1673-5374.280308.

(66) Allen, T. W.; Andersen, O. S.; Roux, B. Energetics of Ion Conduction through the Gramicidin Channel. Proc. Natl. Acad. Sci. U. S. A. 2004, 101 (1), 117-122. https://doi.org/10.1073/pnas.2635314100.

(67) Bostick, D. L.; Brooks, C. L. Selectivity in K+ Channels Is Due to Topological Control of the Permeant Ion's Coordinated State. Proc. Natl. Acad. Sci. 2007, 104 (22), 9260-9265. https://doi.org/10.1073/pnas.0700554104.

(68) Noskov, S. Yu.; Roux, B. Importance of Hydration and Dynamics on the Selectivity of the KcsA and NaK Channels. J. Gen. Physiol. 2007, 129 (2), 135-143. https://doi.org/10.1085/jgp.200609633.

(69) Corry, B.; Thomas, M. Mechanism of Ion Permeation and Selectivity in a Voltage Gated Sodium Channel. J. Am. Chem. Soc. 2012, 134 (3), 1840-1846. https://doi.org/10.1021/ja210020h.

(70) Palascak, M. W.; Shields, G. C. Accurate Experimental Values for the Free Energies of Hydration of $\mathrm{H}+, \mathrm{OH}-$, and H3O+. J. Phys. Chem. A 2004, 108 (16), 3692-3694. https://doi.org/10.1021/jp049914o.

(71) Lamoureux, G.; Roux, B. Absolute Hydration Free Energy Scale for Alkali and Halide Ions Established from Simulations with a Polarizable Force Field. J. Phys. Chem. B 2006, 110 (7), 3308-3322. https://doi.org/10.1021/jp056043p.

(72) Pardridge, W. M. Drug Transport across the Blood-Brain Barrier. J. Cereb. Blood Flow Metab. 2012, 32 (11), 1959-1972. https://doi.org/10.1038/jcbfm.2012.126.

(73) Lochhead, J. J.; Yang, J.; Ronaldson, P. T.; Davis, T. P. Structure, Function, and Regulation of the BloodBrain Barrier Tight Junction in Central Nervous System Disorders. Front. Physiol. 2020, 11, 914. https://doi.org/10.3389/fphys.2020.00914.

(74) Nation, D. A.; Sweeney, M. D.; Montagne, A.; Sagare, A. P.; D’Orazio, L. M.; Pachicano, M.; Sepehrband, F.; Nelson, A. R.; Buennagel, D. P.; Harrington, M. G.; Benzinger, T. L. S.; Fagan, A. M.; Ringman, J. M.; Schneider, L. S.; Morris, J. C.; Chui, H. C.; Law, M.; Toga, A. W.; Zlokovic, B. V. Blood-Brain Barrier Breakdown Is an Early Biomarker of Human Cognitive Dysfunction. Nat. Med. 2019, 25 (2), 270-276. https://doi.org/10.1038/s41591-018-0297-y.

(75) Bocsik, A.; Walter, F. R.; Gyebrovszki, A.; Fülöp, L.; Blasig, l.; Dabrowski, S.; Ötvös, F.; Tóth, A.; Rákhely, G.; Veszelka, S.; Vastag, M.; Szabó-Révész, P.; Deli, M. A. Reversible Opening of Intercellular Junctions of Intestinal Epithelial and Brain Endothelial Cells With Tight Junction Modulator Peptides. J. Pharm. Sci. 2016, 105 (2), 754-765. https://doi.org/10.1016/j.xphs.2015.11.018.

(76) Liao, Z.; Yang, Z.; Piontek, A.; Eichner, M.; Krause, G.; Li, L.; Piontek, J.; Zhang, J. Specific Binding of a Mutated Fragment of Clostridium Perfringens Enterotoxin to Endothelial Claudin-5 and Its Modulation of Cerebral Vascular Permeability. Neuroscience 2016, 327, 53-63. https://doi.org/10.1016/j.neuroscience.2016.04.013.

(77) Piontek, J.; Fritzsche, S.; Cording, J.; Richter, S.; Hartwig, J.; Walter, M.; Yu, D.; Turner, J. R.; Gehring, C.; Rahn, H.-P.; Wolburg, H.; Blasig, I. E. Elucidating the Principles of the Molecular Organization of Heteropolymeric Tight Junction Strands. Cell. Mol. Life Sci. CMLS 2011, 68 (23), 3903-3918. https://doi.org/10.1007/s00018-011-0680-z.

(78) Rossa, J.; Ploeger, C.; Vorreiter, F.; Saleh, T.; Protze, J.; Günzel, D.; Wolburg, H.; Krause, G.; Piontek, J. Claudin-3 and Claudin-5 Protein Folding and Assembly into the Tight Junction Are Controlled by NonConserved Residues in the Transmembrane 3 (TM3) and Extracellular Loop 2 (ECL2) Segments. J. Biol. Chem. 2014, 289 (11), 7641-7653. https://doi.org/10.1074/jbc.M113.531012.

(79) Waterhouse, A.; Bertoni, M.; Bienert, S.; Studer, G.; Tauriello, G.; Gumienny, R.; Heer, F. T.; de Beer, T. A. P.; Rempfer, C.; Bordoli, L.; Lepore, R.; Schwede, T. SWISS-MODEL: Homology Modelling of Protein Structures and Complexes. Nucleic Acids Res. 2018, 46 (W1), W296-W303. https://doi.org/10.1093/nar/gky427.

(80) Xu, D.; Zhang, Y. Improving the Physical Realism and Structural Accuracy of Protein Models by a TwoStep Atomic-Level Energy Minimization. Biophys. J. 2011, 101 (10), 2525-2534. 
bioRxiv preprint doi: https://doi.org/10.1101/2022.03.03.482846; this version posted March 4, 2022. The copyright holder for this preprint (which was not certified by peer review) is the author/funder. All rights reserved. No reuse allowed without permission.

https://doi.org/10.1016/j.bpj.2011.10.024.

(81) Pettersen, E. F.; Goddard, T. D.; Huang, C. C.; Couch, G. S.; Greenblatt, D. M.; Meng, E. C.; Ferrin, T. E. UCSF Chimera--a Visualization System for Exploratory Research and Analysis. J. Comput. Chem. 2004, 25 (13), 1605-1612. https://doi.org/10.1002/jcc.20084.

(82) Heo, L.; Lee, H.; Seok, C. GalaxyRefineComplex: Refinement of Protein-Protein Complex Model Structures Driven by Interface Repacking. Sci. Rep. 2016, 6, 32153. https://doi.org/10.1038/srep32153.

(83) Heo, L.; Park, H.; Seok, C. GalaxyRefine: Protein Structure Refinement Driven by Side-Chain Repacking. Nucleic Acids Res. 2013, 41 (Web Server issue), W384-388. https://doi.org/10.1093/nar/gkt458.

(84) Jorgensen, W. L.; Chandrasekhar, J.; Madura, J. D.; Impey, R. W.; Klein, M. L. Comparison of Simple Potential Functions for Simulating Liquid Water. J. Chem. Phys. 1983. https://doi.org/10.1063/1.445869.

(85) Humphrey, W.; Dalke, A.; Schulten, K. VMD: Visual Molecular Dynamics. J. Mol. Graph. 1996, 14 (1), 33-38, 27-28. https://doi.org/10.1016/0263-7855(96)00018-5.

(86) Jo, S.; Cheng, X.; Islam, S. M.; Huang, L.; Rui, H.; Zhu, A.; Lee, H. S.; Qi, Y.; Han, W.; Vanommeslaeghe, K.; MacKerell, A. D.; Roux, B.; Im, W. CHARMM-GUI PDB Manipulator for Advanced Modeling and Simulations of Proteins Containing Nonstandard Residues. Adv. Protein Chem. Struct. Biol. 2014, 96, 235-265. https://doi.org/10.1016/bs.apcsb.2014.06.002.

(87) Jo, S.; Kim, T.; Iyer, V. G.; Im, W. CHARMM-GUI: A Web-Based Graphical User Interface for CHARMM. J. Comput. Chem. 2008, 29 (11), 1859-1865. https://doi.org/10.1002/jcc.20945.

(88) Wu, E. L.; Cheng, X.; Jo, S.; Rui, H.; Song, K. C.; Dávila-Contreras, E. M.; Qi, Y.; Lee, J.; Monje-Galvan, V.; Venable, R. M.; Klauda, J. B.; Im, W. CHARMM-GUI Membrane Builder toward Realistic Biological Membrane Simulations. J. Comput. Chem. 2014, 35 (27), 1997-2004. https://doi.org/10.1002/jcc.23702.

(89) Phillips, J. C.; Hardy, D. J.; Maia, J. D. C.; Stone, J. E.; Ribeiro, J. V.; Bernardi, R. C.; Buch, R.; Fiorin, G.; Hénin, J.; Jiang, W.; McGreevy, R.; Melo, M. C. R.; Radak, B. K.; Skeel, R. D.; Singharoy, A.; Wang, Y.; Roux, B.; Aksimentiev, A.; Luthey-Schulten, Z.; Kalé, L. V.; Schulten, K.; Chipot, C.; Tajkhorshid, E. Scalable Molecular Dynamics on CPU and GPU Architectures with NAMD. J. Chem. Phys. 2020, 153 (4), 044130. https://doi.org/10.1063/5.0014475.

(90) Feller, S. E.; Zhang, Y.; Pastor, R. W.; Brooks, B. R. Constant Pressure Molecular Dynamics Simulation: The Langevin Piston Method. J. Chem. Phys. 1995, 103 (11), 4613-4621. https://doi.org/10.1063/1.470648.

(91) Martyna, G. J.; Tobias, D. J.; Klein, M. L. Constant Pressure Molecular Dynamics Algorithms. J. Chem. Phys. 1994, 101 (5), 4177-4189. https://doi.org/10.1063/1.467468.

(92) Darden, T.; York, D.; Pedersen, L. Particle Mesh Ewald: An N· $\log (\mathrm{N})$ Method for Ewald Sums in Large Systems. J. Chem. Phys. 1993, 98 (12), 10089-10092. https://doi.org/10.1063/1.464397.

(93) Ryckaert, J.-P.; Ciccotti, G.; Berendsen, H. J. C. Numerical Integration of the Cartesian Equations of Motion of a System with Constraints: Molecular Dynamics of n-Alkanes. J. Comput. Phys. 1977, 23 (3), 327341. https://doi.org/10.1016/0021-9991(77)90098-5.

(94) Miyamoto, S.; Kollman, P. A. SETTLE: An Analytical Version of the SHAKE and RATTLE Algorithm for Rigid Water Models. J. Comput. Chem. 1992, 13 (8), 952-962. https://doi.org/10.1002/jcc.540130805.

(95) Hurwitz, N.; Schneidman-Duhovny, D.; Wolfson, H. J. Memdock: An $\alpha$-Helical Membrane Protein Docking Algorithm. Bioinforma. Oxf. Engl. 2016, 32 (16), 2444-2450. https://doi.org/10.1093/bioinformatics/btw184.

(96) Lyskov, S.; Gray, J. J. The RosettaDock Server for Local Protein-Protein Docking. Nucleic Acids Res. 2008, 36 (Web Server issue), W233-238. https://doi.org/10.1093/nar/gkn216.

(97) Chaudhury, S.; Berrondo, M.; Weitzner, B. D.; Muthu, P.; Bergman, H.; Gray, J. J. Benchmarking and Analysis of Protein Docking Performance in Rosetta v3.2. PloS One 2011, 6 (8), e22477. https://doi.org/10.1371/journal.pone.0022477.

(98) Lyskov, S.; Chou, F.-C.; Conchúir, S. Ó.; Der, B. S.; Drew, K.; Kuroda, D.; Xu, J.; Weitzner, B. D.; Renfrew, P. D.; Sripakdeevong, P.; Borgo, B.; Havranek, J. J.; Kuhlman, B.; Kortemme, T.; Bonneau, R.; Gray, J. J.; Das, R. Serverification of Molecular Modeling Applications: The Rosetta Online Server That Includes Everyone (ROSIE). PloS One 2013, 8 (5), e63906. https://doi.org/10.1371/journal.pone.0063906.

(99) Desta, I. T.; Porter, K. A.; Xia, B.; Kozakov, D.; Vajda, S. Performance and Its Limits in Rigid Body Protein-Protein Docking. Struct. Lond. Engl. 1993 2020, 28 (9), 1071-1081.e3. https://doi.org/10.1016/j.str.2020.06.006.

(100) Vajda, S.; Yueh, C.; Beglov, D.; Bohnuud, T.; Mottarella, S. E.; Xia, B.; Hall, D. R.; Kozakov, D. New 
bioRxiv preprint doi: https://doi.org/10.1101/2022.03.03.482846; this version posted March 4, 2022. The copyright holder for this preprint (which was not certified by peer review) is the author/funder. All rights reserved. No reuse allowed without permission.

Additions to the ClusPro Server Motivated by CAPRI. Proteins 2017, 85 (3), 435-444. https://doi.org/10.1002/prot.25219.

(101) Kozakov, D.; Hall, D. R.; Xia, B.; Porter, K. A.; Padhorny, D.; Yueh, C.; Beglov, D.; Vajda, S. The ClusPro Web Server for Protein-Protein Docking. Nat. Protoc. 2017, 12 (2), 255-278. https://doi.org/10.1038/nprot.2016.169.

(102) Kozakov, D.; Beglov, D.; Bohnuud, T.; Mottarella, S. E.; Xia, B.; Hall, D. R.; Vajda, S. How Good Is Automated Protein Docking? Proteins 2013, 81 (12), 2159-2166. https://doi.org/10.1002/prot.24403.

(103) Xia, B.; Vajda, S.; Kozakov, D. Accounting for Pairwise Distance Restraints in FFT-Based ProteinProtein Docking. Bioinformatics 2016, 32 (21), 3342-3344. https://doi.org/10.1093/bioinformatics/btw306.

(104) Torrie, G. M.; Valleau, J. P. Nonphysical Sampling Distributions in Monte Carlo Free-Energy Estimation: Umbrella Sampling. J. Comput. Phys. 1977, 23 (2), 187-199. https://doi.org/10.1016/00219991(77)90121-8.

(105) Klauda, J. B.; Venable, R. M.; Freites, J. A.; O'Connor, J. W.; Tobias, D. J.; Mondragon-Ramirez, C.; Vorobyov, I.; MacKerell, A. D.; Pastor, R. W. Update of the CHARMM All-Atom Additive Force Field for Lipids: Validation on Six Lipid Types. J. Phys. Chem. B 2010, 114 (23), 7830-7843. https://doi.org/10.1021/jp101759q.

(106) Fiorin, G.; Klein, M. L.; Hénin, J. Using Collective Variables to Drive Molecular Dynamics Simulations. Mol. Phys. 2013, 111 (22-23), 3345-3362. https://doi.org/10.1080/00268976.2013.813594.

(107) Souaille, M.; Roux, B. Extension to the Weighted Histogram Analysis Method: Combining Umbrella Sampling with Free Energy Calculations. Comput. Phys. Commun. 2001, 135 (1), 40-57. https://doi.org/10.1016/S0010-4655(00)00215-0.

(108) Smith, L. G.; Tan, Z.; Spasic, A.; Dutta, D.; Salas-Estrada, L. A.; Grossfield, A.; Mathews, D. H. Chemically Accurate Relative Folding Stability of RNA Hairpins from Molecular Simulations. J. Chem. Theory Comput. 2018, 14 (12), 6598-6612. https://doi.org/10.1021/acs.jctc.8b00633. 